\title{
An experimental and $a b$ initio study on the abiotic reduction of uranyl by ferrous iron
}

S.D. Taylor ${ }^{1}$, M.C. Marcano ${ }^{1}$, K.M. Rosso ${ }^{2}$, and U. Becker ${ }^{1 \mathrm{a}}$

${ }^{1}$ The University of Michigan, Department of Earth and Environmental Sciences, 2534 C. C. Little Building, 1100 North University Ave., Ann Arbor, MI 48109-1005, United States.

${ }^{2}$ Pacific Northwest National Laboratory, Physical Sciences Division, PO Box 999, Richland, WA 99352,

email: ubecker@umich.edu 


\section{Abstract}

It is important to understand the mechanisms controlling the removal of uranyl from solution

3 from an environmental standpoint, particularly whether soluble Fe(II) is capable of reducing soluble

$4 \mathrm{U}(\mathrm{VI})$ to insoluble U(IV). Experiments were performed to shed light into discrepancies of recent

5 studies about precipitation of U-containing solids without changing oxidation states versus

6 precipitation/reduction reactions, especially with respect to the kinetics of these reactions. To

7 understand the atomistic mechanisms, thermodynamics, and kinetics of these redox processes, ab initio

8 electron transfer (ET) calculations, using Marcus theory, were applied to study the reduction of U(VI) aq $_{\text {aq }}$ to

$9 \mathrm{U}(\mathrm{V})_{\mathrm{aq}}$ by Fe(II) $)_{\mathrm{aq}}$ (the first rate-limiting ET-step). Outer-sphere (OS) and inner-sphere (IS) Fe-U

10 complexes were modeled to represent simple species within a homogeneous environment through which

11 ET could occur.

Experiments on the chemical reduction were performed by reacting $1 \mathrm{mM} \mathrm{Fe}(\mathrm{II})_{\mathrm{aq}}$ at $\mathrm{pH} 7.2$ with

13 high (i.e., $0.16 \mathrm{mM}$ ) and lower (i.e., $0.02 \mathrm{mM}$ ) concentrations of $\mathrm{U}(\mathrm{VI})_{\mathrm{aq}}$. At higher $\mathrm{U}$ concentration, a

14 rapid decrease in $\mathrm{U}(\mathrm{VI})_{\mathrm{aq}}$ was observed within the first hour of reaction. XRD and XPS analyses of the

15 precipitates confirmed the presence of (meta)schoepite phases, where up to $\sim 25 \%$ of the original $U$ was

16 reduced to $\mathrm{U}^{4+}$ and/or $\mathrm{U}^{5+}$-containing phases. In contrast, at $0.02 \mathrm{mM} \mathrm{U}$, the $\mathrm{U}(\mathrm{VI})_{\mathrm{aq}}$ concentration

17 remained fairly constant for the first 3 hours of reaction and only then began to decrease due to slower

18 precipitation kinetics. XPS spectra confirm the partial chemical reduction $U$ associated with the

19 precipitate (up to $\sim 30 \%$ ). Thermodynamic calculations support that the reduction of $U(V I)_{\text {aq }}$ to $U(I V)_{\text {aq }}$ by

$20 \mathrm{Fe}(\mathrm{II})_{\mathrm{aq}}$ is energetically unfavorable. The batch experiments in this study show U(VI) is removed from

21 solution by precipitation and that transitioning to a heterogeneous system in turn enables the solid $\mathrm{U}$

22 phase to be partially reduced.

Ab initio ET calculations revealed that OS ET is strongly kinetically inhibited in all cases modeled. OS ET as a concerted proton-coupled ET reaction (ferrimagnetic spin configuration) is thermodynamically favorable $(-35 \mathrm{~kJ} / \mathrm{mol})$, but kinetically inhibited by concurrent proton-transfer $\left(10^{-19}\right.$ $\left.\mathrm{s}^{-1}\right)$. OS ET as a sequential proton-coupled ET reaction is thermodynamically unfavorable $(+102 \mathrm{~kJ} / \mathrm{mol})$ as well as kinetically inhibited, where ET is the rate-limiting step $\left(10^{-12} \mathrm{~s}^{-1}\right)$. In contrast, the reduction of $\mathrm{U}(\mathrm{VI})_{\mathrm{aq}}$ to $\mathrm{U}(\mathrm{V})_{\mathrm{aq}}$ by $\mathrm{Fe}(\mathrm{II})_{\mathrm{aq}}$ as an IS ET reaction is both thermodynamically favorable $(-16 \mathrm{~kJ} / \mathrm{mol})$ and kinetically rapid $\left(10^{8} \mathrm{~s}^{-1}\right)$; the IS ET rate is several orders of magnitude faster than the OS ET rate. Thus,

30 reduction of $\mathrm{U}(\mathrm{VI})_{\mathrm{aq}}$ to $\mathrm{U}(\mathrm{V})_{\mathrm{aq}}$ by $\mathrm{Fe}(\mathrm{II})_{\mathrm{aq}}$ in a homogenous system could occur if an IS Fe-U complex can

31 be achieved. However, the formation of IS Fe-U complexes in an homogeneous solution is predicted to be 32 low; considerable thermodynamic and kinetic barriers exist to proceed from an OS ET reaction to an IS 
1 ET reaction, a process that needs to overcome dehydration of the first solvation shell $(+96 \mathrm{~kJ} / \mathrm{mol})$ and

2 hydrolysis of $\mathrm{Fe}(\mathrm{II})_{\mathrm{aq}}$. The computational results complement and further substantiate experimental results 3 where the reduction of $\mathrm{U}(\mathrm{VI})_{\mathrm{aq}}$ by $\mathrm{Fe}(\mathrm{II})_{\mathrm{aq}}$ does not occur. 


\section{Introduction}

The radioactive element uranium is most soluble and mobile in the hexavalent oxidation state as

3 the uranyl ion $\mathrm{UO}_{2}{ }^{2+}$. Due to its solubility in oxidizing conditions, it is of interest to understand

4 mechanisms that are capable of removing uranyl from solution. There are several mechanisms by which

$5 \mathrm{U}$ can be immobilized in the subsurface. Precipitation of solid uranyl phases such as schoepite

$6 \quad\left(\mathrm{UO}_{3} \cdot 2 \mathrm{H}_{2} \mathrm{O}\right)$ can occur at higher concentrations (e.g., above $\left.10^{-6} \mathrm{M} \mathrm{U}(\mathrm{VI}), \log { }^{*} \mathrm{~K}_{\mathrm{sp}}=5.39\right)$ at near-neutral

7 pH (Jang et al., 2006); schoepite can be found in contaminated sites, such as soils and groundwaters at

8 U.S. Department of Energy sites, as well as in natural U ore deposits. The chemical reduction of U(VI) to

$9 \mathrm{U}(\mathrm{IV})$ is another mechanism to immobilize $\mathrm{U}$, where the tetravalent oxidation state of $\mathrm{U}$ is sparingly

10 soluble and precipitates as uraninite $\mathrm{UO}_{2(\mathrm{~s})}$. An extensive number of studies focus on this approach as it is

11 capable of removing uranyl from solution to below the U.S. Environmental Protection Agency's maximum concentration limits $\left(1.3 \times 10^{-7} \mathrm{M}, 30 \mathrm{ppb}\right)(\mathrm{EPA}, 2000)$.

The abiotic reduction of soluble $\mathrm{U}(\mathrm{VI})$ by soluble Fe(II) as a homogeneous-reaction (i.e., the reduction of $\mathrm{U}(\mathrm{VI})$ by $\mathrm{Fe}(\mathrm{II})$ occurs where both of the reactant species are in the aqueous phase) is a relevant process for retarding $U$ transport in the subsurface. However, experimental results in this area remain inconclusive about the exact mechanism of precipitation or combined reduction/precipitation. One hypothesis is that the reduction of U(VI) in a homogeneous, Fe(II)-containing solution does not occur because the redox reaction is kinetically inhibited. One of the earlier studies investigating the abiotic reduction of uranyl by ferrous iron found that the chemical reduction of $U(V I)$ does not occur in a homogeneous, $\mathrm{Fe}(\mathrm{II})$-containing solution (at neutral $\mathrm{pH}$ in an anoxic system) for over three days, despite being thermodynamically favorable. However, upon addition of hematite nanoparticles $\left(\alpha-\mathrm{Fe}_{2} \mathrm{O}_{3}\right)$ to the solution, the chemical reduction of U(VI) by Fe(II) occurs rapidly, reaching equilibrium during the first hour of reaction (Liger et al., 1999). This phenomenon has also been observed in experiments at similar conditions (i.e., $\mathrm{pH} \sim 7.5$, anoxic environment) using different $\mathrm{U}$ and $\mathrm{Fe}$ concentrations (i.e., $0.1 \mu \mathrm{M}$ to $10 \mu \mathrm{M} \mathrm{U}$, reductant to oxidant ratio of about 500 , growth solution supersaturated with respect to schoepite) (Zeng and Giammar, 2011). Subsequent analyses of these results using surface-complexation models, led to the hypothesis that the reduction of $\mathrm{U}(\mathrm{VI})$ in a homogeneous, $\mathrm{Fe}(\mathrm{II})$-containing solution is

28 kinetically inhibited (Charlet et al., 1998; Liger et al., 1999; Charlet et al., 2002; Zeng and Giammar, 29 2011). These results imply that uranyl reduction at these experimental conditions is not a mechanism by which uranyl will be immobilized. (at neutral pH in an anoxic system) has been reported (Hua et al., 2006; Du et al., 2011). One of the 
hypotheses why uranyl reduction by ferrous iron occurred is that the redox reaction is governed by

2 thermodynamics, where the reaction favorability is dependent on experimental conditions such as $\mathrm{pH}$.

3 Declining concentrations of $\mathrm{Fe}(\mathrm{II})_{\mathrm{aq}}$ correlate with the loss of $\mathrm{U}(\mathrm{VI})_{\mathrm{aq}}$. At the presumed equilibrium $\mathrm{pH}$ of

46.2 , the ratio of consumed Fe(II) to the loss of $\mathrm{U}(\mathrm{VI})$ is $\sim 2: 1$; this ratio would be consistent with a two-

5 electron transfer (ET) to U(VI) and reduction to U(IV). Additionally, thermodynamic calculations with

6 different combinations of $\mathrm{pH},\left[\mathrm{Fe}(\mathrm{II})_{\mathrm{aq}}\right]$, and [U(VI) $\left.)_{\mathrm{aq}}\right]$ predicted uranyl reduction to be favorable for their

7 experimental conditions at $\mathrm{pH}>5$, as was the case for the experimental conditions of $\mathrm{pH} 7.5$ used by

8 Liger et al., (1999). Thus, unlike the experiments where uranyl reduction was not observed, the reduction

9 of uranyl by Fe(II) was found to be thermodynamically and kinetically feasible. These results in turn

10 predict uranyl can be immobilized through reduction to $\mathrm{U}(\mathrm{IV})$ and subsequent precipitation of $\mathrm{UO}_{2(\mathrm{~s})}$.

The studies described above observe very different behaviors for aqueous uranyl and its chemical reduction by ferrous iron (at neutral $\mathrm{pH}$ values in anoxic systems), which can lead to high uncertainties in

13 predicting the transport of $\mathrm{U}$. There is a lack of knowledge in fundamental processes and mechanisms by

14 which uranyl reduction by ferrous iron occurs; this is due to the complexity of the redox environment.

15 The abiotic reduction of $\mathrm{U}(\mathrm{VI})$ is shown to be influenced by a number of processes in an aqueous,

16 homogeneous system, including processes that can convert a homogeneous system to a heterogeneous

17 system (i.e., where $\mathrm{U}$ and/or Fe species can exist as both aqueous and solid phases) (Figure 1, Table 1).

18 The generation of solid redox products, for instance, can enable the possibly rapid transition to a

19 heterogeneous system where the mechanisms involved in removing uranyl from solution are more

20 complex (Figure 1, Table 1, Processes 3-8). Understanding the mechanisms controlling uranyl removal

21 from solution in homogeneous and heterogeneous systems, whether it be schoepite precipitation and/or

22 the chemical reduction of $\mathrm{U}(\mathrm{VI})$ to $\mathrm{U}(\mathrm{IV})$ and subsequent precipitation of $\mathrm{UO}_{2(\mathrm{~s})}$, for example, is

23 necessary to develop more effective pathways for waste isolation and environmental restoration.

Here, experimental and molecular theoretical approaches are applied to understand mechanisms removing uranyl from solution, focusing on whether the chemical reduction of aqueous U(VI) by aqueous $\mathrm{Fe}(\mathrm{II})$ in fact occurs. Experiments were designed using conditions and $\mathrm{U}$ concentrations that can be found in the literature and had produced conflicting results or interpretations. Analyses of the aqueous and solid

28 fractions over time were done to accurately interpret $U$ concentration changes and assess redox

29 mechanisms. Finally, ab initio molecular modeling is applied to explain experimental and geochemical

30 observations. Reduction of U(VI) to U(IV) occurs as a sequential two-ET process; the intermediate

31 oxidation state of $U(V)$ is nominally unstable in solution. It has been postulated that the rate-limiting step

32 is the first ET, reducing $\mathrm{U}(\mathrm{VI})$ to $\mathrm{U}(\mathrm{V})$. Thus for this study, the first ET step for $\mathrm{U}(\mathrm{VI})$ reduction to $\mathrm{U}(\mathrm{V})$

33 by $\mathrm{Fe}(\mathrm{II})$ was specifically investigated. By evaluating molecular mechanisms occurring in both 
homogeneous and heterogeneous systems, this study intends to advance our understanding of environmentally relevant actinide redox reactions.

\section{Methods}

\subsection{Experimental}

\subsubsection{Batch experiments}

All solutions were mixed using degassed water prepared by autoclaving ultrapure Milli- ${ }^{\circledR}$ water (typically $18.2 \mathrm{M} \Omega \cdot \mathrm{cm}$ at $25^{\circ} \mathrm{C}$ ) in Pyrex ${ }^{\circledR}$ Corning ${ }^{\circledR C}$ glass bottles at regular sterilizing conditions (i.e., 40 minutes at $121^{\circ} \mathrm{C}$ and $\sim 138 \mathrm{kPa}$ ). Out of the autoclave, purified $\mathrm{N}_{2}$ is blown onto and bubbled into the water for about 90 minutes while it cools from $\sim 95^{\circ} \mathrm{C}$ to $\sim 35^{\circ} \mathrm{C}$ in a warm bath. Glass bottles are then air-tight capped and immediately transferred to a controlled atmosphere $\mathrm{Coy}^{\circledR}$ vinyl glove box. Gas in the box $(5 \% \mathrm{H}$ in $\mathrm{N}$ mix $)$ is kept dry and at $\mathrm{O}$ levels $<1 \mathrm{ppm}$ using a desiccant and a palladium catalyst attached to a continuously running fan box. $\mathrm{O}$ is further removed by recirculating the glove box atmosphere through an $\mathrm{O}$ trap using a diaphragm pump.

Stock solutions of $0.05 \mathrm{M} \mathrm{UO}_{2}{ }^{2+}$ and $0.18 \mathrm{M} \mathrm{Fe}^{2+}$ were prepared from high-purity solids $\mathrm{UO}_{2}\left(\mathrm{NO}_{3}\right)_{2} \cdot 6 \mathrm{H}_{2} \mathrm{O}$ (International Bio-Analytical Industries Inc.; CAS-\#: 13520-83-7) and $\mathrm{FeCl}_{2}$ (SigmaAldrich; 99.998\% trace metal basis; CAS-\#: 7758-94-3) in 1\% $\mathrm{HNO}_{3}$ and $\mathrm{HCl}$, respectively. Experiments were conducted at $\mathrm{pH} \sim 7.2$, where the solution $\mathrm{pH}$ was buffered by $5 \mathrm{mM}$ HEPES and the ionic strength was controlled at $50 \mathrm{mM} \mathrm{NaCl}$. Intermediate $0.82 \mathrm{mM} \mathrm{UO}_{2}{ }^{2+}$ and $5 \mathrm{mM} \mathrm{Fe}$ (II) stock solutions were prepared in $5 \mathrm{mM}$ HEPES- $50 \mathrm{mM} \mathrm{NaCl}(\mathrm{pH}=7.5)$ solution, further titrated with $0.1 \mathrm{M} \mathrm{NaOH}$ to $\mathrm{pH}$ $\sim 7.2$, and equilibrated overnight. After equilibration, solutions were filtered through $0.22 \mu \mathrm{m}$ pore-size PVDF syringe filter membranes. The $5 \mathrm{mM}$ Fe(II) solution prepared this way was used in both Experiments 1 and 2 (described below). The equilibrated $0.82 \mathrm{mM} \mathrm{UO}_{2}{ }^{2+}$ solution was used only for Experiment 2, while the titration information served to make a second $\mathrm{UO}_{2}{ }^{2+}$ intermediate stock at reaction time for Experiment 1.

Experiments were conducted at conditions similar to those where the chemical reduction of uranyl have and have not been observed; Du et al., (2011) observed the chemical reduction of $0.20 \mathrm{mM}$

$28 \mathrm{U}(\mathrm{VI})$ in a $1 \mathrm{mM} \mathrm{Fe}^{2+}$-containing solution while Zeng and Giammar (2011) did not observe uranyl 29 reduction at $0.01 \mathrm{mM} \mathrm{U}(\mathrm{VI})$ in a $5 \mathrm{mM} \mathrm{Fe}^{2+}$-containing solution. Similar concentrations were used in this study, $0.16 \mathrm{mM}$ and $0.02 \mathrm{mM} \mathrm{U}$, to further probe the mechanisms controlling removal of uranyl from 
uranyl reduction occurring in a homogeneous system and the subsequent precipitation of $\mathrm{UO}_{2(\mathrm{~s})}$ or via other mechanisms such as precipitation of $\mathrm{U}(\mathrm{VI})$ solid phases.

For Experiment 1 (predicted to be thermodynamically-favorable and kinetically-rapid conditions for uranyl reduction by Du et al., (2011)), a neutral reaction solution ( $\mathrm{pH}$ 7.2) of $1 \mathrm{mM} \mathrm{Fe}^{2+}$ and $0.16 \mathrm{mM}$ $\mathrm{UO}_{2}{ }^{2+}$ was prepared in $5 \mathrm{mM}$ HEPES- $50 \mathrm{mM} \mathrm{NaCl}$ solvent using the intermediate $5 \mathrm{mM} \mathrm{Fe}^{2+}$ stock solution (equilibrated overnight and filtered) and $0.05 \mathrm{M} \mathrm{UO}_{2}{ }^{2+}$ stock solution.

For Experiment 2 (predicted to be thermodynamically-favorable but kinetically-slow conditions for uranyl reduction by Zeng and Giammar (2011)), a neutral reaction solution ( $\mathrm{pH} 7.2)$ of $1 \mathrm{mM} \mathrm{Fe}^{2+}$ and $0.02 \mathrm{mM} \mathrm{UO}_{2}{ }^{2+}$ was prepared in $5 \mathrm{mM}$ HEPES- $50 \mathrm{mM} \mathrm{NaCl}$ solvent, using the intermediate $\mathrm{Fe}$ and $\mathrm{U}$ stock solutions (both equilibrated and filtered). The filtered U stock solution was used to ensure uranyl in the system was present only in its aqueous state.

The solutions for both experiments were constantly agitated on a sample rotator. Aliquots of $3 \mathrm{ml}$ were taken from the reactors at $0,15,30,45$ minutes and 1.5, 3, 5, 8, 24, 32, 48, and 72 hours from the 14 beginning of the experiment. The aliquots were filtered through $0.22 \mu \mathrm{m}$ pore size PVDF syringe filter membranes acidified to $1 \% \mathrm{HNO}_{3}$, and reserved for analysis by ICP-MS. The solution $\mathrm{pH}$ was measured at 0 and 45 minutes and 3,8,24, 48, and 72 hours to observe if the acidity of the solution was increasing via the generation of solid (redox) products. Solid samples were also collected on the $0.22 \mu \mathrm{m}$ pore size PVDF syringe filter membranes at 0 and 45 minutes and 3, 8, 24, 48, and 72 hours to observe the rate of uranyl reduction occurring over time. Precipitate samples were dried on filter membranes in a dessicator under anoxic conditions in the glove box, and were set aside for XRD and/or XPS analysis.

Aqueous $\mathrm{Fe}^{2+}$ and $\mathrm{UO}_{2}{ }^{2+}$ concentrations were measured from the diluted, acidified aliquots using a Perkin-Elmer ELAN DRC-e ICP-MS. The identity of Fe analyzed with the ICP was confirmed to be $\mathrm{Fe}^{2+}$, as $\mathrm{UV}-\mathrm{V}$ is measurements using the ferrozine method provided similar $\mathrm{Fe}^{2+}$ concentrations (within $5 \%$ error). The quantitative analysis method used ten sweeps per reading, five readings per replicate, and the average of five replicates per measurement, simple linear standard calibration curve with 6 points, and $\mathrm{Ga}$ as internal standard. Analytical precision was better than 3\% RSD for both U and Fe based on check standards, laboratory reference material, and sample replicates. Internal standard variation was never above $15 \%$.

To determine the thermodynamics for Fe-U redox reactions, geochemical information, such as the chemical speciation of $\mathrm{Fe}^{2+}$ and $\mathrm{UO}_{2}{ }^{2+}$ at the given experimental conditions, was derived using the software Visual Minteq (Gustafsson, 2010). It was of particular interest to determine the thermodynamics 
1 for redox reactions where both the Fe and $\mathrm{U}$ reactants and products are in the aqueous phase, similar to

2 what was done by Felmy et al., (2011). Because the solubilities of $\mathrm{Fe}^{3+}$ and $\mathrm{U}^{4+}$ are low, with respect to

3 their corresponding oxides, redox reactions are often expressed as $\mathrm{UO}_{2}{ }^{2+}{ }_{(\mathrm{aq})}+2 e-\rightarrow \mathrm{UO}_{2(\mathrm{~s})}$, for instance,

4 where the reactant is one phase (aqueous) and the product is a different phase (solid). However, if

5 considering a truly homogeneous system, aqueous reactants should yield aqueous products immediately

6 following the redox process (e.g., $\left.\mathrm{UO}_{2}{ }^{2+}{ }_{(\mathrm{aq})}+2 e^{-} \rightarrow \mathrm{U}^{4+}{ }_{(\mathrm{aq})}\right)$. Thus, thermodynamic calculations with

7 products in both the aqueous and solid states were used to determine the feasibility of redox reactions

8 occurring in homogeneous solution and the potential influence of solid phases on the reaction free energy.

Standard electrode potentials $\left(p e^{0}\right)$ for $\mathrm{UO}_{2}{ }^{2+} / \mathrm{U}^{4+}\left(p e^{0}{ }_{l}=9.038\right)$ and $\mathrm{Fe}^{2+} / \mathrm{Fe}^{3+}\left(p e^{0}=13\right)$ were used to calculate redox potentials $p e_{1}$ and $p e_{2}$, respectively (Morel and Hering, 1993) (Eqn. 1):

$$
p e=p e^{0}-\log \frac{[\text { Reductant }]}{[\text { Oxidant }]}
$$

The experimental conditions used were: $\mathrm{Fe}^{2+}=6.8 \times 10^{-4} \mathrm{M}, \mathrm{Fe}^{3+}=3.2 \times 10^{-4} \mathrm{M}, \mathrm{UO}_{2}{ }^{2+}=7 \times 10^{-7} \mathrm{M}$

13 (based on experimental data in this study), $\mathrm{U}^{4+}=1.6 \times 10^{-4} \mathrm{M}$ (assuming all uranium is reduced to $\mathrm{U}^{4+}$ by

14 two- $\left.\mathrm{Fe}^{2+}\right), \mathrm{pH}=7.2$. While the $\mathrm{UO}_{2}{ }^{2+} / \mathrm{U}^{4+}$ equilibrium is $\mathrm{pH}$ dependent because it involves the coupled proton transfer of $4 \mathrm{H}^{+}$ions, the $\mathrm{UO}_{2}{ }^{2+} / \mathrm{U}(\mathrm{OH})_{4}$ is not and the transition between these two equilibria can be performed using the hydrolysis of the $\mathrm{U}(\mathrm{OH})_{4}$ complex. At these conditions, the primary electron

17 donor from $\mathrm{Fe}^{2+}$-containing species (e.g., $\left.\mathrm{FeCl}^{+}, \mathrm{FeCl}_{2}\right)$ is $\mathrm{Fe}^{2+}\left(\sim 98 \%\right.$ of the aqueous $\mathrm{Fe}^{2+}$ species) and the $\mathrm{UO}_{2}{ }^{2+}$ electron acceptor species are $\left(\mathrm{UO}_{2}\right)_{3}(\mathrm{OH})_{5}{ }^{+}(\sim 65 \%),\left(\mathrm{UO}_{2}\right)_{4}(\mathrm{OH})_{7}^{+}(\sim 32.5 \%)$, and $\mathrm{UO}_{2}(\mathrm{OH})_{2}$

$19(\sim 1.5 \%)$. Redox products were chosen based on dominant aqueous and solid redox species; the aqueous redox products were $\mathrm{U}(\mathrm{OH})_{4}$ and $\mathrm{Fe}(\mathrm{OH})_{2}{ }^{+}$and the solid redox products used were $\mathrm{Fe}(\mathrm{OH})_{3}, \alpha-\mathrm{FeOOH}$, $\alpha-\mathrm{Fe}_{2} \mathrm{O}_{3}$, and $\mathrm{UO}_{2(\mathrm{am}, \mathrm{s})}$. An amorphous, solid $\mathrm{UO}_{2}$ phase was chosen based on experimental observations of faster precipitation kinetics than crystalline $\mathrm{UO}_{2}$ (Felmy et al., 2011). Thermodynamic data for aqueous hydrolysis species were calculated using hydrolysis constants supplied by Visual Minteq's thermodynamic database (Gustafsson, 2010). The reaction free energy, $\Delta G$, for a two-ET redox reaction was calculated from the redox potentials derived from the various combinations of reactant and product species (Eqn. 2):

$$
\Delta G=-n \times 2.3 R T\left(p e_{1}-2 \times p e_{2}\right)
$$

28 where $n$ is the number of electrons transferred (two in this case), $R$ is the gas constant $\left(8.314 \mathrm{~J} \mathrm{~mol}^{-1} \mathrm{~K}^{-1}\right)$, and $T$ is temperature in Kelvin $(298.15 \mathrm{~K})$. 


\subsubsection{Analyses of the solids}

X-ray diffraction (XRD) analyses were performed on selected samples to determine the identity of the solid (redox) products formed. Again, precipitate samples had been dried on filter membranes in a dessicator under anoxic conditions. XRD spectra were acquired using a step size of $0.02^{\circ} 2 \theta$ and a scan rate of $0.02^{\circ}$ s from $5^{\circ}$ to $60^{\circ} 2 \theta$ on a Scintag X1 Powder X-Ray Diffractometer with Cu-K $\alpha$ source. Background from the PVDF filters was subtracted from the XRD spectra.

A Philips XL30 FEG scanning electron microscope (SEM) was used to observe uranyl precipitation at the lower uranyl concentration $(0.02 \mathrm{mM} \mathrm{U})$. Dried filter membranes were carbon-coated and mounted using double-sided copper-tape. A thin strip of graphite paste was also painted on the filtermembranes to the sample mount to reduce the amount of charging on the nonconductive filter membranes. Images were collected using a beam current of $15 \mathrm{keV}$. Backscattered electron (BSE)

12 imaging was used to identify solid precipitates on the filter membrane and energy-dispersive spectroscopy

13 (EDS) spectra with an EDAX Genesis detector was used to confirm the presence of uranium in the 14 precipitates observed.

Characterization of the chemical oxidation states of uranium was done by measuring electron binding energies (BEs) using a Kratos Axis Ultra X-ray photoelectron spectrometer (XPS) with an Al-K $\alpha$ $\mathrm{x}$-ray radiation source $(1486.6 \mathrm{eV})$. The dried powders on the filter membranes (exposed only to the anoxic glove bag atmosphere) were transferred in a Cole-Parmer vacuum dessicator during transit to avoid exposure to atmosphere. The filters with the powders were affixed onto double-sided copper tape and loaded onto a sample bar. This is the only time where samples could have been exposed to atmosphere for up to 2 - 4 minutes. The samples were degassed in the sample-transfer chamber under a vacuum pressure of $<10^{-5}$ Torr overnight, to ensure degassing of the PVDF filters. Upon transferring the samples to the sample-analysis chamber, a vacuum pressure of $<10^{-8}$ Torr was maintained. The $\mathrm{x}$-ray emission current and anode voltage used during spectra acquisition were $8 \mathrm{~mA}$ and $14 \mathrm{keV}$, respectively. A charge neutralizer was used during spectra acquisition due to the non-conductive behavior of the filters and powdered samples. Spectra were acquired using a hybrid lens and slot aperture $(700 \times 300 \mu \mathrm{m})$.

Survey scans were collected to confirm the presence of relevant elements in this study (U, C, O, $\mathrm{Fe}$ ) in the $\mathrm{BE}$ range -5 to $1200 \mathrm{eV}$ at 1 sweep (dwell time $=200 \mathrm{~ms}$ ) and at a pass energy of $160 \mathrm{eV}$.

29 Following the survey scans, narrow scans were collected under the same analyzer conditions, but at lower 30 pass energies and with more sweeps to better resolve photopeak energies. Samples from Experiment 1

31 were collected using a pass energy of $20 \mathrm{eV}$ while samples from the Experiment 2 used $80 \mathrm{eV}$ (the lower 32 concentrations of uranyl produced lower counts); narrow scans for U used 15 - 20 sweeps (dwell 
time $=133 \mathrm{~ms}$ ). The presence of $\mathrm{U}, \mathrm{O}, \mathrm{C}$, and $\mathrm{F}$ (from the PVDF filters) was apparent and narrow scans could be acquired. Fe $2 p$ photopeaks could not be found or resolved with survey or narrow scans (BE $\sim 710 \mathrm{eV}$ ), despite estimated Fe cps suggesting Fe was detectable in samples for Experiment 1 (based on the ratio of Fe removed from solution to uranium removed from solution).

XPS spectra were analyzed using the Casa XPS software (v. 2.3.16). Spectra were calibrated using the adventitious carbon method (Hochella, 1988); the energy for the $\mathrm{C} 1 \mathrm{~s}$ photopeak led to a shift in energy from $\sim 282.5$ to $285 \mathrm{eV}$. Narrow scans for the $\mathrm{U} 4 \mathrm{f}$ photopeaks were analyzed in detail to characterize uranium oxidation states. Within a simple (oxy)hydroxide system, the $\mathrm{U} 4 \mathrm{f} \mathrm{BE}$ can be used to distinguish between $\mathrm{U}(\mathrm{VI})$ and more reduced $\mathrm{U}$ phases, where a higher BE represents the higher U(VI) oxidation state (Hochella, 1988). BEs for different chemical oxidations of uranium can overlap, in which case satellite peaks (if present) are used to provide more concrete determination of the oxidation state.

12 Quantification of the amounts of reduced uranyl on the solids collected over time were also compared to

13 aqueous data to understand whether the aqueous data accurately reflected the amount of reduction 14 occurring. Shirley background subtraction was applied to U 4f spectra with Gaussian-Lorentzian (GL) 15 type curves fit to the photopeaks and satellite peaks. The FWHM for the components fit to the photopeaks 16 were held constant and so was the FWHM for the components fit to the satellite peaks (though not 17 necessarily the same FWHM as the photopeaks).

\subsection{Computational}

The aim of the ab initio calculations was to estimate the thermodynamics and kinetics of the first ET step in Fe-U complexes found in aqueous, homogeneous systems. An aquo $\mathrm{Fe}^{2+}$ complex $\left(\mathrm{Fe}\left(\mathrm{H}_{2} \mathrm{O}\right)_{6}{ }^{2+}\right)$ and hydrated, octahedrally-coordinated $\mathrm{UO}_{2}(\mathrm{OH})_{2}$ complex were constructed, consistent with their expected speciation at neutral $\mathrm{pH}$ (Figure 2a, 2b). The uranyl species at higher concentrations at neutral $\mathrm{pH}$ also exist as hydroxypolymers $\left(\right.$ e.g., $\left.\left(\mathrm{UO}_{2}\right)_{3}(\mathrm{OH})_{5}{ }^{+}\right)$, although using these polynuclear species would significantly complicate the ab initio calculations ( e.g., reduction of the entire complex would require 25 six-ET steps). At lower uranyl concentrations, the neutral $\mathrm{UO}_{2}(\mathrm{OH})_{2}$ species is the major dissolved 26 species and is sufficient for these calculations. An outer-sphere $(\mathrm{OS})$ complex $\mathrm{Fe}\left(\mathrm{H}_{2} \mathrm{O}\right)_{6}{ }^{2+}$ -

$27 \mathrm{UO}_{2}(\mathrm{OH})_{2}\left(\mathrm{H}_{2} \mathrm{O}\right)_{2}$ was modeled to represent the ions in an aqueous environment being fully solvated while 28 an inner-sphere (IS) complex $\left(\left(\mathrm{H}_{2} \mathrm{O}\right)_{4} \mathrm{Fe}(\mathrm{OH})_{2}-\mathrm{UO}_{2}\left(\mathrm{H}_{2} \mathrm{O}\right)_{2}\right)^{2+}$ represents the dehydration of the OS 29 complex and complexation of the ions through bridging-hydroxyl ligands. The IS complex is the 30 predicted complex through which uranyl reduction can occur, and is also relevant to heterogeneous 31 systems (Charlet et al., 1998; Liger et al., 1999; Charlet et al., 2002; Sherman et al., 2008; Singh et al., 32 2012). 
Ab initio calculations were applied to ET reactions to reduce $\mathrm{UO}_{2}{ }^{2+}$ to $\mathrm{UO}_{2}{ }^{+}$by $\mathrm{Fe}^{2+}$, using the

2 speciation as above, and in the gas-phase (i.e., only the first hydration shell is explicitly treated). Marcus

3 Theory has been used as a framework for environmental ET calculations using molecular modeling for

4 over a decade (Rosso et al., 2003, 2004; Iordanova et al., 2005; Rosso and Dupuis, 2006; Wander et al.,

5 2006; Wander and Schoonen, 2010); detailed explanations of Marcus Theory and the calculation of ET

6 rates are available in the literature, which the reader is referred to for more information (Marcus and

7 Sutin, 1985; Farazdel et al., 1990; Marcus, 1993; Rosso et al., 2003). To model an ET reaction, the Fe ${ }^{2+}$

8 and $\mathrm{UO}_{2}{ }^{2+}$ ion must be assigned with the appropriate charges and spin configurations. Before ET occurs,

9 the $\mathrm{Fe}^{2+}$ ion has a net charge and spin of +2 and +4 , respectively, while the $\mathrm{UO}_{2}{ }^{2+}$ ion has a net charge and

10 spin of +2 and 0 , respectively; this state is referred to as the pre-ET complex in this study. After ET, the

11 oxidized $\mathrm{Fe}^{2+}$ (now $\mathrm{Fe}^{3+}$ ) would have a net charge and spin of +3 and +5 , respectively, while the reduced

$12 \mathrm{UO}_{2}{ }^{2+}$ (now $\mathrm{UO}_{2}{ }^{+}$) is +2 and \pm 1 ; this state is referred to as the post-ET complex. Ferromagnetic (same

13 majority spin direction for $\mathrm{Fe}^{3+}$ and $\mathrm{UO}_{2}{ }^{+}$) and ferrimagnetic (opposite majority spin directions for $\mathrm{Fe}^{3+}$

14 and $\mathrm{UO}_{2}{ }^{+}$with a net residual moment) spin configurations for the post-ET complex were modeled to

15 determine the most energetically favorable spin configuration as well as observe whether the spin configuration affects the thermodynamics and kinetics of ET.

The pre- and post-ET structures were geometry optimized using NWChem (Valiev et al., 2010).

18 Basis sets used in this study were 6-31G** (O and H) (Harihara.Pc and Pople, 1973), Ahlrichs PVDZ

19 (Fe) (Schafer et al., 1992), and the Stuttgart RLC ECP (U) (Küchle et al., 1991); the reliability of these

20 basis sets has been demonstrated in other studies (Kerisit and Rosso, 2006; Wander et al., 2006;

21 Skomurski et al., 2011). The structures were pre-optimized using spin-unrestricted Hartree-Fock (HF) to

22 localize the electrons in the desired distribution, and then re-optimized using the HF-DFT hybrid B3LYP

23 functional to improve the exchange-correlation description and produce more accurate wavefunctions and

24 structures. Only the results of the DFT-B3LYP calculations are presented in this study, except for

25 electronic coupling matrix elements which were calculated at the HF level.

Changes in Mulliken spin distributions for the optimized pre- and post-ET structures, as

28 monitored to confirm the appropriate oxidation state was obtained. Average bond lengths between $\mathrm{Fe}(\mathrm{III})$

29 and its hydroxyl or water ligands, as well as average bond lengths between U(VI) and its oxo, hydroxyl,

30 and water ligands, are shorter than those for the $\mathrm{Fe}(\mathrm{II})$ and $\mathrm{U}(\mathrm{V})$ cations, respectively, due to the electron

31 localization (Rosso et al., 2003). 
Following optimization of the pre- and post-ET structures, a potential energy (PE) profile was

2 derived from single-point energies calculated from hybrid structures, obtained using the linear

3 synchronous transit method (LST) (Halgren and Lipscomb, 1977) (Figure 3). Parabolic functions were fit

4 to the reactant and product PE surfaces to derive ET parameters, namely the free energy of ET reaction,

5 the reorganization energy, and the diabatic activation energy. The reaction free energy, $\Delta G^{0}$, is the change

6 in free energy upon ET. The reorganization energy, $\lambda$, is the energy needed to distort the configuration of

7 the reactants into that of the products without changing the electronic distribution. From these data the

8 electronic coupling matrix element and adiabaticity of the reaction were also determined. reactant and product states at the transition state (calculated using HF wavefunctions using the ET module in NWChem). It should also be noted that the more strenuous Stuttgart RSC basis set for U (Dolg et al., 1993) was used in the $V_{A B}$ calculations to produce more reliable values. The magnitude of $\mathrm{V}_{\mathrm{AB}}$ determines if the reaction proceeds adiabatically (the electronic coupling is strong; $V_{A B}>k_{B} T$ ) or nonadiabatically (weak; $V_{A B}<k_{B} T$ ) (Skomurski et al., 2011).

Additionally the probability for ET to occur, $P_{12}$, is a function of $V_{A B}$ and $\lambda$ (Eqn. 3):

$$
P_{12}=1-\exp \left(\left(-\frac{V_{a b}^{2}}{h v}\right) \sqrt{\frac{\pi^{3}}{\lambda k_{B} T}}\right)
$$

17 where $h$ is Planck's constant $\left(4.14 \times 10^{-15} \mathrm{eV} \cdot \mathrm{s}\right), v$ is the typical frequency for nuclear motion $\left(10^{13} \mathrm{~s}^{-1}\right)$

18 (Wander et al., 2006), $k_{B}$ is the Boltzmann's constant $\left(8.62 \times 10^{-5} \mathrm{eV} / \mathrm{K}\right)$, and $T$ is the temperature in

19 Kelvin $(273 \mathrm{~K}) . P_{12}$ is another indication of whether a reaction occurs adiabatically or nonadiabatically: if the probability is high $(\sim 1)$, ET occurs adiabatically and vice versa. transition state configuration, and can be estimated for the adiabatic case as (Eqn. 4):

$$
\Delta G^{*}=\frac{\left(\lambda+\Delta G^{0}\right)^{2}}{4 \lambda}-V_{A B}
$$

If the electronic coupling is strong, the ET reaction occurs adiabatically and the ET rate, $k_{E T}$, is expressed as (Eqn. 5):

$$
k_{E T}=v e^{\frac{-\Delta G *}{k_{B} T}}
$$

If the electronic coupling is weak, the ET reaction occurs nonadiabatically and $k_{E T}$ is expressed as (Eqn. 6): 


$$
k_{E T}=\frac{2 \pi}{\hbar}\left|V_{A B}\right|^{2} \frac{1}{\sqrt{4 \pi \lambda k_{B} T}} \exp \left(-\frac{\left(\Delta G^{0}+\lambda\right)^{2}}{4 \pi \lambda k_{B} T}\right)
$$

.

The OS-ET reaction was found to be complicated as energy minimization of the product state shows that proton transfer (PT) is coupled to the ET. Proton-coupled electron transfer (PCET) was also observed in calculations for the reduction of triscarbonato uranyl by $\mathrm{Fe}^{2+}$ (Wander et al., 2006). To understand the rates of elementary steps involved, Wander et al., (2006) treated the OS-ET as two different models, as a concerted-PCET reaction $\left(\mathrm{PCET}_{\text {conc }}\right)$ and as a sequential-PCET $\left(\mathrm{PCET}_{\text {seq }}\right)$ reaction. The $\mathrm{PCET}_{\text {conc }}$ reaction describes ET and PTs occurring simultaneously while the $\mathrm{PCET}_{\text {seq }}$ reaction describes ET to occur first and was followed by PT. Separating the ET from the PT led to significantly different thermodynamics and ET rates for the reduction of triscarbonato uranyl by $\mathrm{Fe}^{2+}$. More so, the comparison between the two different models enabled the authors to conclude that the ET step of the PCET $_{\text {seq }}$ was rate-limiting (Wander et al., 2006). This approach was adopted into the present study; the two different models were applied to the OS-complex in the ferrimagnetic spin configuration. The PE surfaces for the $\mathrm{PCET}_{\text {seq }}$ reaction showed different curvatures between the ET step and the PT step (i.e., the curvature for the PT was steeper). Thus, $\lambda$ values for the PT were calculated with both the shallow and steep curvatures, providing a range of values for $\lambda, \Delta G^{*}, V_{A B}$, and $k_{E T}$.

The reaction energy to proceed from an OS complex to an IS complex was calculated as a dehydration reaction (Eqn. 7):

$$
\mathrm{Fe}\left(\mathrm{H}_{2} \mathrm{O}\right)_{6}^{2+}-\mathrm{UO}_{2}(\mathrm{OH})_{2}\left(\mathrm{H}_{2} \mathrm{O}\right)_{2} \leftrightarrow\left(\left(\mathrm{H}_{2} \mathrm{O}\right)_{4} \mathrm{Fe}(\mathrm{OH})_{2}-\mathrm{UO}_{2}\left(\mathrm{H}_{2} \mathrm{O}\right)_{2}\right)^{2+}+2 \mathrm{H}_{2} \mathrm{O} \quad \Delta \mathrm{E}_{\text {dehydration }}(7)
$$

The gas-phase energetics for the dehydration reaction were corrected for aqueous solution conditions by calculating the energy for the water molecule with the COnductor-like Screening MOdel (COSMO) (Klamt and Schuurmann, 1993; Delley, 2006), as the energy of a water molecule is significantly better described by including solvation interactions. COSMO corrections for the metal species were found to cancel due to large and similar cavity sizes and identical net charge.

\section{Results}

\subsection{Experimental Results}

\subsubsection{Experiment 1: Thermodynamically favorable and kinetically rapid conditions}


At conditions where uranyl reduction had been observed ( $0.16 \mathrm{mM} \mathrm{U}(\mathrm{VI}), 1 \mathrm{mM} \mathrm{Fe}(\mathrm{II}))$, the aqueous uranium concentration decreases rapidly during the first 15 minutes of reaction. Within the first hour of reaction, the concentration decreases by an order of magnitude (i.e., from $0.16 \mathrm{mM}$ to $0.02 \mathrm{mM}$ $\mathrm{UO}_{2}{ }^{2+}$ ) (Figure $4 \mathrm{a}, 4 \mathrm{c}$ ). After 8 hours of reaction, $\mathrm{U}(\mathrm{VI})_{\text {aq }}$ reaches an equilibrium concentration of $\sim 7 \times 10^{-7}$ M, which remained constant until the experiment's completion. In agreement with previous studies (Du et al., 2011), the removal of aqueous $\mathrm{U}$ in a $\mathrm{Fe}^{2+}$-containing solution at near-neutral $\mathrm{pH}$ under anoxic conditions occurs rapidly.

$\mathrm{Fe}^{2+}$ concentrations were measured concurrently to assess whether they correlated with changes in uranyl concentrations. Such a correlation would suggest chemical reduction and eventual precipitation of $\mathrm{UO}_{2(\mathrm{~s})}$. $\left[\mathrm{Fe}(\mathrm{II})_{\mathrm{aq}}\right]$ show a decreasing trend similar to that of $\left[\mathrm{U}(\mathrm{VI})_{\mathrm{aq}}\right]$ (Figure $4 \mathrm{~b}, 4 \mathrm{c}$ ). However the proportion of $\mathrm{Fe}$ to $\mathrm{U}$ removed is 1.4 to 1 instead of the expected 2 to 1 ratio, considering simple mass and electron balance for reduction to U(IV) (Figure 4d). Thus, $\mathrm{Fe}^{2+}$ concentrations indicate only partial reduction of $\mathrm{U}(\mathrm{VI})$. Assuming the loss of $\mathrm{Fe}^{2+}$ is due exclusively to chemical reduction, an estimated maximum of $\sim 0.02 \mathrm{mM} \mathrm{U}(\mathrm{VI})(\sim 13 \%)$ is reduced at 45 minutes and $\sim 0.06 \mathrm{mM} \mathrm{U}(\mathrm{VI})(\sim 38 \%)$ by 72 hours.

The $\mathrm{pH}$ decreased from 7.19 to 7.09 within the first 8 hours, but remained constant at $\mathrm{pH} 7.09$ from 8 hours onward to 72 hours of reaction. The $\mathrm{pH}$ changes also correlate to [U(VI) $\left.)_{\mathrm{aq}}\right]$ changes, where the U(VI) concentration reached equilibrium after 8 hours, as mentioned above. This decrease in $\mathrm{pH}$ is in agreement with the generation of solid (redox) products, such as the precipitation of iron oxides and of uranium phases including schoepite and uraninite; these processes increase the acidity of the solution as discussed below.

Analyses of aqueous uranyl concentrations show uranyl is removed from solution over time, though the mechanism(s) controlling uranyl removal from solution are uncertain. Decreasing Fe(II) concentrations indicate partial $\mathrm{U}(\mathrm{VI})$ reduction occurred, though it is unclear if reduction occurred in a homogeneous environment (where aqueous $\mathrm{U}(\mathrm{VI})$ is reduced by aqueous $\mathrm{Fe}(\mathrm{II})$ ) or in a heterogeneous environment (where formation of iron or uranyl-containing solids in turn facilitate $U$ reduction). Control experiments were conducted to show whether a homogeneous system was maintained. After equilibration, both $0.17 \mathrm{mM} \mathrm{UO}_{2}{ }^{2+}$ and $1 \mathrm{mM} \mathrm{Fe}^{2+}$ stock solutions at $\mathrm{pH} 7.2$ were filtered through syringe filters (25 $\mathrm{mm}$-diameter PTFE membrane, $0.22 \mu \mathrm{m}$ pore size), which were set aside for solid analyses. Equilibration of the $1 \mathrm{mM} \mathrm{Fe}^{2+}$ solution at $\mathrm{pH} 7.2$ showed little to no $\mathrm{Fe}^{2+}$ was removed from solution after filtration, over 24 hours. The precipitation of green rust or iron redox products did not occur under these conditions. Conversely, the concentration of the $0.17 \mathrm{mM} \mathrm{UO}_{2}{ }^{2+}$ solution decreased to $0.05 \mathrm{mM} \mathrm{U}$ within the first 1.5 
hours (similar to the rate the in uranyl concentration decreases in the Fe-U experiment). A uniform

2 coating of bright-yellow precipitates was observed on the filter, and the solids were characterized to be

3 predominantly (meta)schoepite using XRD ( $74 \%$ schoepite, $\sim 16 \%$ metaschoepite, and $\sim 10 \% \beta$ -

$\left.4 \quad \mathrm{UO}_{2}(\mathrm{OH})_{2}\right)$ (Figure 5).

These control experiments show the precipitation of (meta)schoepite to be the primary mechanism controlling uranyl removal from solution. Geochemical models also indicate the system being supersaturated with respect to schoepite (Figure 6). The removal of uranyl could not be attributed to the chemical reduction of soluble $\mathrm{U}(\mathrm{VI})$ by soluble Fe(II) as concluded by previous experiments (Du et al., 2011). It is thus expected that any chemical reduction of U(VI) by Fe(II) at these conditions is a result of catalytic effects supplied by the solid substrate. This conclusion supports previous results where U(VI) reduction by $\mathrm{Fe}(\mathrm{II})$ is observed to occur only in heterogeneous systems (Liger et al., 1999; Zeng and Giammar, 2011).

XPS analyses on the solid fractions were used to observe whether the chemical reduction of uranyl by ferrous iron had occurred. Powders covered the filters uniformly and facilitated XPS analyses. The U 4f XP spectra for the solid samples collected at 45 minutes and up to 72 hours showed clear asymmetry in the $U$ ff $7 / 2$ and 5/2 peaks, indicating more than one oxidation state of uranium being present (Figure 7a). GL curves were fit at $381.7 \pm 0.2$ and $380.7 \pm 0.2 \mathrm{eV}$ BEs (Figure $7 \mathrm{~b}$ ). The component peak at $381.7 \mathrm{eV}$ is attributed to $\mathrm{U}(\mathrm{VI})$. U(VI) is the predominant oxidation state of the solid, as shown by the higher intensity of the U(VI) component peak as well as the clear observance of U(VI) satellite peaks (Figure $7 \mathrm{~b}$, Table 2); the satellite for $7 / 2$ peak is at $385.6 \mathrm{eV}$ and the satellites for the $5 / 2$ peaks are at 396.7 and $402.8 \mathrm{eV}$. It should also be noted that the $\mathrm{BE}$ for the $\mathrm{U}(\mathrm{VI})$ phase measured is lower than BEs reported for typical uranyl oxide phases such as schoepite $(382.3 \mathrm{eV})$; this energy difference is possibly due to more complex bonding environments on the surface of the solid where $\mathrm{U}(\mathrm{VI})-\mathrm{O}-\mathrm{U}(\mathrm{V}, \mathrm{IV})$ bonds, for instance, may exist.

The lower BE component peak at $380.7 \mathrm{eV}$ is associated with the reduced uranyl fraction, though it is difficult to attribute the peak to a single uranium oxidation state. $U(I V)$ and $U(V)$ can be difficult to distinguish because the BEs of their (pure) oxides partially overlap (379.8-380.5 eV for U(IV) oxides; $380.1 \pm 1 \mathrm{eV}$ for $\mathrm{U}(\mathrm{V})$ oxides) (limited information on $\mathrm{U}(\mathrm{V})$ oxides is available) (Allen et al., 1974; Wersin et al., 1994; Ilton and Bagus, 2011). Satellite features are often more helpful to discriminate between these oxidation states, though clear U(IV) or U(V) satellite peaks could not be observed in the spectra collected due to the small fraction of reduced uranyl present. Faint $U(V)$ 4f 7/2 satellites (388.7 \pm 0.2) were visible in some spectra (i.e., 45 minutes, 24 hours, 72 hours), suggesting the chemically reduced 
uranyl portion may be $\mathrm{U}(\mathrm{V})$, though it was difficult to observe the $5 / 2$ satellite due to background noise.

2 Unfortunately, not enough information was available from the XPS analyses to determine the ratio

3 between the concentrations of $\mathrm{U}(\mathrm{V})$ and/or $\mathrm{U}(\mathrm{IV})$ present.

The reduced uranyl portion after 45 minutes reaction time is estimated to be up to $\sim 24 \%$ of the total uranium present (Table 2). After 72 hours, the proportion of reduced U increases slightly to $\sim 26 \%$. The small changes in the reduced uranyl proportions show the chemical reduction of U(VI) within the near surface of (meta)schoepite occurs rapidly and little uranyl is reduced after 45 minutes. Thus, rapid reduction of uranyl occurs at the surface of the (meta)schoepite; uranyl is rapidly precipitated from solution at the beginning of the experiment as (meta)schoepite where the formation of a solid facilitates adsorption of $\mathrm{Fe}(\mathrm{II})$ onto the surface of the bulk $\mathrm{U}$ phase. This result is reminiscent of heterogeneous experiments where reduction occurs at a timescale of hours (Liger et al., 1999; Zeng and Giammar, 2011). Additionally, the formation of a passivation layer of reduced species on the schoepite surface is believed to inhibit further reduction of uranyl within the bulk of the solid $\mathrm{U}$ phase (Fredrickson et al., 2000; Duff et al., 2002).

The estimated reduced uranyl proportions based on the decrease of $\mathrm{Fe}^{2+}$ concentrations in batch experiments (analyzed by ICP-MS) somewhat disagree with those derived from XPS solid analyses. As mentioned earlier, assuming the amount of $\mathrm{Fe}^{2+}$ removed from solution was lost entirely to the chemical reduction of uranyl, the resulting Fe to $U$ ratios would erroneously lead to the belief that up to $\sim 13 \%$ of uranyl was reduced to $\mathrm{U}(\mathrm{IV})(\sim 0.02 \mathrm{mM} \mathrm{U})$ after 45 minutes and $\sim 38 \%$ of uranyl was reduced to U(IV) (or $\sim 0.06 \mathrm{mM} \mathrm{U}$ ) after 72 hours. The XPS data indicate instead that up to $\sim 24 \%$ of the uranyl was reduced ( $\sim 0.04 \mathrm{mM} \mathrm{U})$ within the first 45 minutes, and it is not certain whether complete reduction to U(IV) occurred. While quantification of the reduced uranyl proportion from XPS analysis is less accurate than those using aqueous methods such as ICP-MS, the XPS data imply a fraction of the Fe(II) removed from solution did not participate in uranyl reduction. It is plausible that a portion of $\mathrm{Fe}(\mathrm{II})$ removed from solution and not involved in the chemical reduction of uranyl may have precipitated with iron oxide redox products. $\mathrm{Fe}(\mathrm{III})$ generated from the oxidation of $\mathrm{Fe}(\mathrm{II})$ and reduction of $\mathrm{mM}$ to $\mu \mathrm{M}$ amounts of $\mathrm{U}(\mathrm{VI})$ would be well above the saturation limit of several iron oxides such as magnetite $\left(\mathrm{Fe}_{3} \mathrm{O}_{4}\right)$.

Characterization of the iron redox products is relevant to deciphering the mechanisms and processes that concern this study. Unfortunately, the scarcity of solids collected prevented the identification of potential iron redox products using either XPS or XRD. The relevance of characterizing these redox products will be revisited in the discussion.

\subsubsection{Experiment 2: Thermodynamically favorable but kinetically slow conditions}


For conditions where uranyl reduction had not been observed ( $0.02 \mathrm{mM} \mathrm{U}(\mathrm{VI}), 1 \mathrm{mM} \mathrm{Fe}(\mathrm{II}))$ (Zeng and Giammar, 2011), [U(VI) $\left.)_{\mathrm{aq}}\right]$ is constant for the first 3 hours of reaction, suggesting uranyl remains in the aqueous phase (Figure 4a, 4c). However, after 3 hours, [U(VI) aq] decreased by micromolar amounts $(<5 \mu \mathrm{M})$ and after 24 hours about $50 \%$ of the aqueous uranyl $(0.01 \mathrm{mM})$ is removed from solution. At 72 hours, the uranyl concentration reaches $1.8 \times 10^{-7} \mathrm{M}$, close to the analytical limit of detection $\left(1.6 \times 10^{-7} \mathrm{M} \mathrm{U}, 0.3 \mathrm{ppb}\right)$ and near schoepite's solubility limit.

$\mathrm{Fe}^{2+}$ concentrations were measured concurrently to assess whether uranyl reduction was 8 occurring. $\left[\mathrm{Fe}(\mathrm{II})_{\mathrm{aq}}\right]$ remain fairly constant during the 72-hour reaction period (Figure 4b, 4c), as 9 expected. The amount of Fe(II) required to chemically reduce all the U(VI) present is within the 10 analytical error; reduction of the $0.02 \mathrm{mM} \mathrm{U}(\mathrm{VI})$ would lead to a less than $4 \%$ change in the $\mathrm{Fe}^{2+}$ 11 concentrations, which is within the error of the measurements (5\%). Consequently, changes in $\mathrm{Fe}^{2+}$ 12 concentrations could not be used as a proxy for chemical reduction. The stability of the $\mathrm{Fe}^{2+}$ 13 concentrations indicates that the loss of $\mathrm{Fe}^{2+}$ would be due to the production of only small amounts of $14 \mathrm{Fe}^{3+}$ redox products. $\mathrm{pH}$ measurements also do not indicate significant generation of solid (redox) 15 products; the $\mathrm{pH}$ remained constant at $7.18 \pm 0.3$ over the 72 -hour reaction (within the error of the $\mathrm{pH}$ 16 meter).

(Meta)schoepite precipitates were not visible to the naked eye at these concentrations in contrast to those observed in Experiment 1. To test whether precipitation was occurring, a control experiment for $190.02 \mathrm{mM} \mathrm{U}(\mathrm{VI})$ at $\mathrm{pH} 7.2$ was conducted, similar to the experiment conducted for the $0.17 \mathrm{mM} \mathrm{U}(\mathrm{VI})$ 20 solution. The solution was equilibrated, with solids collected on filters at 3 and 24 hours using $0.02 \mu \mathrm{m}$ 21 Anopore aluminum oxide membranes (Whatman Anotop syringe filters) to ensure collection of 22 nanoparticulate uranium precipitates. SEM imaging was used to confirm precipitation of uranium solids. 23 The filter at the 3-hour sampling time did not show uranium precipitates (Figure 8a). However, the filter 24 for the 24-hour sample contained clumped aggregates of rod-shaped precipitates, generally longer than $25500 \mathrm{~nm}$; EDS identified the precipitates to be a uranium oxide (Figure 8b). This is in agreement with the 26 aqueous data where uranyl remained in the aqueous phase for the first 3 hours and considerable 27 precipitation occurred after 24 hours. Thus, uranyl reduction by ferrous iron at these experimental 28 conditions is again predicted to occur via heterogeneous pathways that involve reaction on or catalysis by surfaces in contact with solution.

Solids collected on the filters were sparsely found, making it difficult to obtain high-quality XP 31 spectra. U 4f spectra on samples from 45 minutes to 8 hours were broad, noisy, and difficult to quantify 32 (not shown in Figure $7 \mathrm{c}$ ). Distinct $U$ 4f peaks appeared in correlation to removal of $\sim 50 \%$ of the aqueous 
uranyl from solution (i.e., from 24 hours onwards) (Figure 7c). The U 4f 7/2 and 5/2 peaks showed

2 asymmetry, implying the presence of uranium in more than one oxidation state. GL curves were fit for the

$3 \mathrm{U} 4 \mathrm{f} 7 / 2$ peak with BEs of $381.5 \pm 0.1 \mathrm{eV}(\mathrm{U}(\mathrm{VI})$ phase) and at $380.4 \pm 0.1 \mathrm{eV}$ (reduced uranyl phase).

4 The predominant oxidation state of the solid was U(VI) based on the higher intensity component peak at

$5 \quad 381.5 \mathrm{eV}$ and faint $\mathrm{U}(\mathrm{VI})$ satellite peaks for the $7 / 2$ peak at $385.0 \mathrm{eV}$ and the $5 / 2$ peak at 396.1 and 402.6

$6 \mathrm{eV}$. The oxidation state of the reduced uranyl fraction at $380.4 \mathrm{eV}$ is again less distinct; satellite peaks for

$7 \mathrm{U}(\mathrm{V})$ and $\mathrm{U}(\mathrm{IV})$ were inseparable from the background noise. At 24 hours, an estimated $30-33 \%$ of the

8 total uranium present was in the reduced phase (Table 2); the uranyl proportions remained constant at 48

9 and 72 hours suggesting that most of the reduction occurred within the first 24 hours. This is again

10 consistent with uranyl reduction occurring rapidly at the onset of U(VI) precipitation.

These experimental results suggest that uranyl reduction is facilitated by the formation of a

12 heterogeneous system. Thermodynamic calculations are compared to these observations to better

13 understand whether uranyl is capable of being reduced by ferrous iron in a homogeneous system (Figure

14 9). Redox reaction thermodynamics (at the given experimental conditions) were calculated to be

15 endothermic when aqueous redox products (i.e., $\mathrm{Fe}(\mathrm{OH})_{2}{ }^{+}$and $\mathrm{U}(\mathrm{OH})_{4}$ ) were produced, regardless of the

16 aqueous reactant species used (Figure 9) (Eqn. 8). The thermodynamic favorability of the redox reaction

17 is heavily influenced by the formation of solid redox products, particularly the formation of specific $\mathrm{Fe}^{3+}$

18 solids. For instance, uranyl reduction to $\mathrm{U}(\mathrm{OH})_{4(\mathrm{aq})}$ was endothermic when coupled with formation of

$19 \mathrm{Fe}(\mathrm{OH})_{3(\mathrm{~s})}\left(\right.$ Eqn. 9) but was exothermic with the formation of $\mathrm{Fe}_{2} \mathrm{O}_{3(\mathrm{~s})}$ (Eqn. 10) (again regardless of the

20 aqueous reactant species used).

$212 \mathrm{Fe}^{2+}+\frac{1}{3}\left(\mathrm{UO}_{2}\right)_{3}(\mathrm{OH})_{5}^{+}+\frac{13}{3} \mathrm{H}_{2} \mathrm{O} \rightarrow 2 \mathrm{Fe}(\mathrm{OH})_{2}^{+}+\mathrm{U}(\mathrm{OH})_{4}+\frac{7}{3} \mathrm{H}^{+} \quad \Delta \mathrm{G}=+161 \mathrm{~kJ} / \mathrm{mol}$

$2 \mathrm{Fe}^{2+}+\frac{1}{3}\left(\mathrm{UO}_{2}\right)_{3}(\mathrm{OH})_{5}^{+}+\frac{19}{3} \mathrm{H}_{2} \mathrm{O} \rightarrow 2 \mathrm{Fe}(\mathrm{OH})_{3(s)}+\mathrm{U}(\mathrm{OH})_{4}+\frac{13}{3} \mathrm{H}^{+} \quad \Delta \mathrm{G}=+19 \mathrm{~kJ} / \mathrm{mol}$

$2 \mathrm{Fe}^{2+}+\frac{1}{3}\left(\mathrm{UO}_{2}\right)_{3}(\mathrm{OH})_{5}^{+}+\frac{10}{3} \mathrm{H}_{2} \mathrm{O} \rightarrow \mathrm{Fe}_{2} \mathrm{O}_{3(s)}+\mathrm{U}(\mathrm{OH})_{4}+\frac{13}{3} \mathrm{H}^{+}$

$\Delta \mathrm{G}=-46 \mathrm{~kJ} / \mathrm{mol}$

These thermodynamic results are in agreement with Felmy et al., (2011) where the free energy of the $\mathrm{Fe}^{3+}$ reaction product is a key factor in determining the conditions where $\mathrm{UO}_{2}{ }^{2+}$ can be reduced by

$26 \mathrm{Fe}^{2+}$. Additionally, this study and Felmy et al., (2011) predict uranyl reduction by ferrous iron in a

27 homogeneous system (where reactants and products are all in the aqueous phase) is not

28 thermodynamically favorable at near-neutral $\mathrm{pH}$ values. These calculations further support experimental

29 observations of uranyl reduction being facilitated in heterogeneous systems. They also show the 
importance of accounting for the aqueous redox products to form before the solid phases, as this approach leads to considerably different conditions where uranyl reduction by $\mathrm{Fe}^{2+}$ is thermodynamically favorable.

In summary, the removal of uranyl from solution in a homogeneous, ferrous-iron containing solution is from the precipitation of (meta)schoepite, not from the chemical reduction of uranyl by ferrous iron in aqueous phase and the subsequent precipitation of $\mathrm{UO}_{2(\mathrm{~s})}$. The creation of a heterogeneous system following uranium precipitation creates an environment conducive towards the chemical reduction of uranyl by ferrous iron. This supports previous experimental results where the chemical reduction of uranyl by ferrous iron occurs in heterogeneous systems, such as in the presence of iron oxides (Liger et al., 1999; Zeng and Giammar, 2011). Further clarity for why uranyl reduction by ferrous iron in a homogeneous system is not observed will be provided through the thermodynamics and kinetics of molecular-scale ET reactions mechanisms modeled using ab initio methods.

\subsection{Computational results}

\section{$13 \quad 3.2 .1$. Outer-sphere ET thermodynamics and kinetics}

Structures for pre- and post-ET OS-complexes were geometry optimized using a DFT-B3LYP 15 approach (Figure 10a, 10b). Electron localization was assessed by Mulliken spin density distributions.

16 Mulliken spin densities for the $\mathrm{Fe}^{2+}$ and $\mathrm{UO}_{2}{ }^{2+}$ ions in the pre-ET model were approximately +3.85

17 (formal spin of +4 ) and $0(0)$, respectively, while for the $\mathrm{Fe}^{3+}$ and $\mathrm{UO}_{2}{ }^{+}$ions in the post-ET models, they

18 were approximately $+4.26(+5)$, and $\pm 1.12( \pm 1)$, respectively (the negative sign of the $U$ spin indicates the

19 spin direction is opposite to the Fe spin direction). Additionally, the bond distances reflect the correct

20 oxidation states for both the pre- and post-ET models, where shorter average bond lengths are observed

21 for the $\mathrm{Fe}^{3+}$ and $\mathrm{U}^{6+}$ in comparison to $\mathrm{Fe}^{2+}$ and $\mathrm{U}^{5+}$, respectively (Table 3); larger bond length changes are incurred in cations where the electron is localized.

In addition to the respective lengthening and shortening of bonds for each model, the optimized structures show the reduction of U(VI) to $\mathrm{U}(\mathrm{V})$ by Fe(II) as an OS complex proceeds as a PCET reaction. The ET from the Fe(II) to the $\mathrm{U}(\mathrm{VI})$ is accompanied by spontaneous transfer of two protons. After ET, the uranyl molecule was hydrated from $\mathrm{UO}_{2}(\mathrm{OH})_{2}\left(\mathrm{H}_{2} \mathrm{O}\right)_{2}$ to $\mathrm{UO}_{2}\left(\mathrm{H}_{2} \mathrm{O}\right)_{4}{ }^{+}$; each of the hydroxyl ligands of the uranyl molecule acquired a hydrogen atom from water ligands associated with the iron complex. The aquo $\mathrm{Fe}^{2+}$ complex was hydrolyzed from $\mathrm{Fe}\left(\mathrm{H}_{2} \mathrm{O}\right)_{6}{ }^{2+}$ to $\mathrm{Fe}(\mathrm{OH})_{2}\left(\mathrm{H}_{2} \mathrm{O}\right)_{4}{ }^{+}$. This is in agreement with the

29 chemical speciation and behavior of ferric iron in solution where water molecules, when bound to $\mathrm{Fe}^{3+}$, are Bronsted-Lowry acids and hydrolyze to induce the formation of ferric iron hydroxide species. 
From the geometry-optimized structures and their total energies for the pre- and post-ET systems, 2 the thermodynamics and kinetics for the ET from $\mathrm{Fe}^{2+}$ to $\mathrm{UO}_{2}{ }^{2+}$ were determined. The free energy of the 3 PCET $_{\text {conc }}$ reaction was exothermic for the ferromagnetic and ferrimagnetic cases $(-19$ and $-35 \mathrm{~kJ} / \mathrm{mol}$, 4 respectively). Based on just the free energy of reaction, the first ET step would be plausible for U(VI) to 5 be reduced by $\mathrm{Fe}(\mathrm{II})$ in a homogeneous system. The thermodynamics differ between the computational 6 and empirical calculations; thermodynamic calculations using empirical data predict uranyl reduction to 7 be energetically unfavorable in a homogeneous system (as presented above) while these ab initio 8 calculations suggest the first ET step occurs. Thermodynamic calculations using empirical calculations 9 account for more extensive hydrolysis reactions and changes in speciation of the reduced products (e.g., $\left.10 \mathrm{UO}_{2}{ }^{2+}+2 e-\rightarrow \mathrm{U}(\mathrm{OH})_{4}\right)$. The molecular computational models provide a quantum-level understanding of 11 uranyl reduction and the thermodynamics reflect the energetics of atomistic redox-reaction mechanisms.

Even though the ET reaction is thermodynamically downhill, the kinetics of the reaction are 13 predicted to be slow; the coupling of two PTs to the ET for the ferromagnetic and ferrimagnetic cases 14 yield vanishingly small (effectively zero) rates, $\sim 10^{-21}$ and $4 \times 10^{-19} \mathrm{~s}^{-1}$, respectively (Figure 10c, Table 4). 15 Additionally, only the ferromagnetic case proceeds adiabatically $\left(V_{A B}=9.9 \mathrm{~kJ} / \mathrm{mol}\right)$, though the predicted 16 rate remains negligible. These slow rates are due to a persistent tendency for the ET reaction to be 17 coupled to spontaneous PTs, requiring substantial structural rearrangement through bond breaking and 18 reforming that accompanies the redistribution of the electron density. The activated complex is thus 19 characterized by a nuclear configuration involving two $\mathrm{H}^{+}$ions dissociated from water molecules in 20 transit relatively long distances (because of the OS encounter complex treatment) to the uranium 21 hydration sphere. High reorganization energies $(+707$ and $+769 \mathrm{~kJ} / \mathrm{mol}$ for the ferromagnetic and 22 ferrimagnetic models, respectively) and activation energies ( +192 and $+176 \mathrm{~kJ} / \mathrm{mol}$, respectively) are incurred by the significant structural rearrangement of the OS complex. We consider our calculated energetics to be maximum values, as the LST method to determine the reaction coordinates does not ensure an energy minimized pathway. It is possible that second-shell waters could provide lower energy pathways for PT, particularly in the OS encounter complex, though these are not included in our treatment. Nonetheless, the coupled PTs and hydrolysis of the aquo Fe molecule lead to considerable energetic barriers affecting the ET rate for the OS PCET conc $_{\text {system. }}$

Treatment of the OS ET as a $\mathrm{PCET}_{\text {seq }}$ reaction was also done to observe the ET energetics without 30 the energetic contributions from the spontaneous PTs; U(VI) was first reduced to U(V) (an intermediate 31 structure, using a ferrimagnetic spin configuration for this calculation) with the PTs following the ET 32 step. To model the post-ET state without PT occurring concurrently, all $\mathrm{OH}$ bond distances (excluding 33 hydrogen bonds) were fixed relative to the $\mathrm{O}$ atoms in the pre-ET state and the structure was energy 
minimized. In this treatment, the energetic barriers for ET are lowered; the activation energy decreases by $\sim 50 \mathrm{~kJ} / \mathrm{mol}$ to $+117 \mathrm{~kJ} / \mathrm{mol}$ and the reorganization energy decreases by $\sim 500 \mathrm{~kJ} / \mathrm{mol}$ to $+210 \mathrm{~kJ} / \mathrm{mol}$ (Figure 10d, Table 4). This confirms that a substantial contribution to the activation energy in the $\mathrm{PCET}_{\text {conc }}$ treatment arises from the dissociation of $\mathrm{OH}$ bonds. However, the ET step for the $\mathrm{PCET}_{\text {seq }}$ treatment is thermodynamically unfavorable $(+102 \mathrm{~kJ} / \mathrm{mol})$ due to the steric constraints placed on the system. Thus, although the rate of ET from Fe(II) to U(VI) increases through a PCET seq $_{\text {reaction }}$ mechanism, the ET rate remains slow $\left(3 \times 10^{-12} \mathrm{~s}^{-1}\right)$.

The second step of PCET $_{\text {seq }}$, involving PTs and the structural rearrangement of the OS complex, is exothermic $(-134 \mathrm{~kJ} / \mathrm{mol})$ and is characterized by lower activation energies than the ET step ( +84 to +8 $\mathrm{kJ} / \mathrm{mol}$ ); these trends are expected given that the ET has increased the negative charge density on the uranium ion. However, the overall $\mathrm{PCET}_{\text {seq }}$ reaction would be limited by the slower of the two component rates in the sequential mechanism - the ET step. It thus appears that the tendency for the $\mathrm{Fe}^{3+}$ molecule to hydrolyze during ET leads to a configurational barrier that hinders U(VI) reduction by Fe(II) as an OS encounter complex.

\subsubsection{Inner sphere ET thermodynamics and kinetics}

As was done with the OS models, the structures for the pre- and post-ET IS models were geometry optimized (Figure 11a, 11b). Correct oxidation states were also confirmed through analysis of Mulliken spin density distributions (pre-ET: $\mathrm{Fe}^{2+} \approx+3.83$ and $\mathrm{UO}_{2}{ }^{2+} \approx-0.01$; post-ET: $\mathrm{Fe}^{3+} \approx+4.25$ and $\mathrm{UO}_{2}{ }^{+} \approx \pm 1.15$ ) and through assessment of calculated bond distances. Interatomic distances for the IS complex are also in good agreement with experimental results; e.g., our Fe-U distance is $\sim 3.5 \AA$, which is similar to experimentally-measured Fe-U distances observed for uranyl adsorbed on iron (oxyhydr)oxides as an IS complex (3.44 - $3.49 \AA$ ) (Waite et al., 1994; Sherman et al., 2008; Singh et al., 2012).

Similar to the OS PCET conc model, the reduction of $U(V I)$ to $U(V)$ is found to be thermodynamically favorable for both the ferromagnetic and ferrimagnetic models $(-16 \mathrm{~kJ} / \mathrm{mol}$ for both reactions) (Figure 11c, Table 4). In contrast to the OS complex, the IS complex does not exhibit spontaneous PT accompanying ET. In turn, the energetic parameters and the kinetics are not affected by large energetic contributions from the $\mathrm{OH}$ dissociation. The activation energies are low in comparison to those for all of the OS models $(+38$ and $+33 \mathrm{~kJ} / \mathrm{mol}$ for the ferromagnetic and ferromagnetic models, respectively). The reorganization energies for the IS models are also considerably lower than those

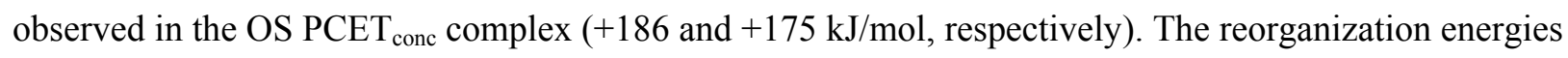
are close to those obtained for the ET step of the OS PCET seq model; this is reasonable because in both cases the absence of PTs means that internal reorganization energy arises primarily from small 
adjustments to bond lengths and angles in the Fe-U encounter complex. The energetic barriers for ET are thus shown to be significantly reduced upon formation of a hydroxyl-ligand bridge between the uranyl and ferrous iron ions. In turn, the resulting ET rates for the ferromagnetic and ferrimagnetic reactions are calculated to be orders of magnitude faster than the OS rates $\left(2 \times 10^{4}\right.$ and $3 \times 10^{8} \mathrm{~s}^{-1}$, respectively). More so, the ferrimagnetic ET proceeds adiabatically $\left(V_{A B}=9.8 \mathrm{~kJ} / \mathrm{mol}\right)$ and would represent the most likely pathway for ET to occur in the IS complex.

$\mathrm{U}(\mathrm{VI})$ reduction by $\mathrm{Fe}(\mathrm{II})$ in a homogeneous system is calculated to be thermodynamically favorable and kinetically feasible when $\mathrm{U}$ and Fe form an IS encounter complex via bridging-hydroxyl ligands. This suggests that ET between U(VI) and Fe(II) is highly dependent on the ease by which an IS complex may form. Our molecular computations address the thermodynamic favorability for an OS complex to transition to an IS complex (via Eqn. 7), where it is found that $+96 \mathrm{~kJ} / \mathrm{mol}$ of energy is required to remove two water molecules from the OS complex to become an IS complex. Thus, based on the thermodynamic unfavorability for an OS Fe-U complex to dehydrate and form an IS complex, the formation of an IS Fe-U complex within which ET may proceed is predicted to be exceptionally low in an aqueous, homogenous solution.

\section{Discussion}

The experimental results are in agreement with previous studies where the removal of uranyl at high concentrations is observed. However, the mechanisms for the removal of uranyl were not attributed to the chemical reduction of aqueous uranyl and subsequent precipitation of $\mathrm{UO}_{2(\mathrm{~s})}$ as in Du et al., (2011) (Figure 1; Table 1; Processes 2, 5, 6). In contrast, this study indicates the removal of uranyl due to the precipitation of (meta)schoepite and the subsequent transitioning to a heterogeneous system further enabled uranyl reduction by ferrous iron (Figure 1; Table 1; Processes 3, 7). These results support solubility data (Figure 6) as well as results from previous studies concluding that the chemical reduction of U(VI) by Fe(II) proceeds rapidly in heterogeneous systems, such as uranyl and ferrous iron coadsorbed onto iron oxide minerals (Liger et al., 1999; Zeng and Giammar, 2011). These batch experiments show $\mathrm{U}(\mathrm{VI})$ is removed from solution by precipitation and that transitioning to a heterogeneous system enables uranyl reduction to occur, where the surface of the solid $U$ phase is partially reduced to U(IV) and/or $\mathrm{U}(\mathrm{V})$. This study also shows redox reaction thermodynamics are endothermic in a truly homogeneous system, where aqueous redox products (i.e., $\mathrm{Fe}(\mathrm{OH})_{2}{ }^{+}$and $\left.\mathrm{U}(\mathrm{OH})_{4}\right)$ are produced.

To substantiate experimental observations, ab initio methods and ET calculations provide further thermodynamic and kinetic data as well as an understanding of molecular-scale reaction mechanisms 
significantly. The progression of $\mathrm{U}(\mathrm{VI})$ reduction to $\mathrm{U}(\mathrm{V})$ as a PCET reaction leads to high energetic

2 barriers and in turn slow ET rates. These rates and energetics are in agreement with values obtained for

3 ET between $\mathrm{Fe}^{2+}$ and uranyl-carbonate complexes (Wander et al., 2006). In contrast, achieving an IS

4 complex through bridging hydroxyl ligands enables rapid reduction of $\mathrm{U}(\mathrm{VI})$ to $\mathrm{U}(\mathrm{V})$. This is in

5 agreement with surface complexation models predicting U(VI) reduction by Fe(II) to proceed as an IS

6 reaction, based on the formation of IS oxidant and reductant complexes on iron (hydr)oxide surfaces

7 (Charlet et al., 1998; Liger et al., 1999; Charlet et al., 2002). Furthermore, the ease with which ET

8 proceeds in an IS complex also supports the rapid reduction rates observed in heterogeneous systems on

9 (hydr)oxide minerals, where the reduction rates have been directly proportional to the concentration of

10 hydroxylated $\mathrm{Fe}^{2+}$ surface complexes (Charlet et al., 1998; Liger et al., 1999). However, our study

11 suggests that formation of the IS complex necessary for facile ET in homogeneous aqueous solution is

12 unfavorable. These models provide a fundamental understanding of why reduction for the homogeneous

13 uranyl-ferrous iron system is rarely observed.

The ab initio models are in agreement with other experimental observations such as the hydrolysis of $\mathrm{Fe}^{2+}$ and its enhanced reactivity; the aquo $\mathrm{Fe}^{2+}$ ion in the OS complex undergoes hydrolysis 16 with and/or during ET, resulting in a hydroxylated $\mathrm{Fe}^{3+}$ ion. It is well known that hydrolysis of $\mathrm{Fe}^{2+}$

17 increases the oxidation rate; deprotonation of the aquo $\mathrm{Fe}^{2+}$ ion causes an accelerated oxidation rate by a 18 factor of $10^{4}$ and $\mathrm{Fe}(\mathrm{OH})_{2}$ reacts $10^{5}$ times faster than $\mathrm{Fe}(\mathrm{OH})^{+}$(Wehrli et al., 1989). The precipitation of 19 (uranyl) oxide phases can also facilitate the hydrolysis of divalent cations including $\mathrm{Fe}^{2+}$ compared to 20 solution (Schindler, 1991), in turn accelerating its oxidation rate (Wehrli et al., 1989; Charlet et al., 21 2002). Surface complexation models also predict uranyl reduction by ferrous iron to be kinetically 22 inhibited, where $\mathrm{Fe}^{2+}$ hydrolysis and formation of a redox precursor-complex such as a binary $\mathrm{Fe}-\mathrm{U}$ 23 complex, are some of the postulated barriers (Wehrli et al., 1989; Schindler, 1991; Liger et al., 1999).

24 These atomistic mechanisms are observed for the OS ET models in this study and are shown to have a considerable impact on the ET reaction thermodynamics and kinetics, whereby the IS complex is the product of overcoming these energetic barriers.

Chemical speciation also significantly influences whether reduction can occur via homogeneous 28 pathways. The IS complex is less thermodynamically favorable than the OS complex, thus the formation 29 of IS complexes would be limited in an aqueous system. The lowered stability of the IS complex is likely 30 due to repulsive Coulombic forces between the positively charged $\mathrm{Fe}^{2+}$ and $\mathrm{UO}_{2}{ }^{2+}$ species (Rosso and 31 Morgan, 2002). Our results suggest that homogeneous reduction may be significantly limited due to the 32 unfavorability of IS interactions between Fe(II) and U(VI). Similarly, it is also plausible that the 33 homogeneous reduction of metals such as $\mathrm{Cr}(\mathrm{VI})$ and $\mathrm{Tc}(\mathrm{VII})$ by $\mathrm{Fe}(\mathrm{II})$ are facilitated through the 
attraction, collision, and complexation between oppositely charged ions $\left(\mathrm{CrO}_{4}{ }^{2-}\right.$ and $\mathrm{TcO}_{4}{ }^{-}$and $\left.\mathrm{Fe}^{2+}\right)$

2 (Zachara et al., 2007; Wander and Schoonen, 2010). For instance, the free energy to bring two, oppositely

3 charged $\mathrm{CrO}_{4}^{-2}$ and $\mathrm{Fe}^{2+}$ ions together is approximately $-23 \mathrm{~kJ} / \mathrm{mol}$ (Wander and Schoonen, 2010) while

4 this study would predict 0 to $+20 \mathrm{~kJ} / \mathrm{mol}$ for $\mathrm{UO}_{2}(\mathrm{OH})_{2} / \mathrm{UO}_{2}{ }^{2+}$ and $\mathrm{Fe}^{2+}$ species. Thus, while the reduced

5 uranyl and oxidized $\mathrm{Fe}^{2+}$ products may be thermodynamically favorable, the formation of an IS complex

6 is unfavorable (in comparison to other metal systems such as $\operatorname{Cr}(\mathrm{VI})$ and $\mathrm{Tc}(\mathrm{VII})$ ) based on the chemical

7 speciation.

For future studies, it is important to address areas of analysis that can be improved upon so that more accurate observations and predictions of uranyl reduction can be made. Analysis of the aqueous $\mathrm{U}(\mathrm{VI})$ fraction can lead to inaccurate predictions of the mechanisms governing uranyl removal from

11 solution. Studies often correlate aqueous U(VI), extracted U(VI) (via the bicarbonate method) (Waite et

12 al., 1994; Gabriel et al., 1998), and loss of aqueous Fe(II) to quantify the amount of uranyl reduced.

13 Stoichiometric relationships between the consumption of Fe(II) and removal of U(VI) help determine

14 whether the chemical reduction of uranyl is occurring (Eary and Rai, 1988; Hua et al., 2006; Hua and

15 Deng, 2008; Du et al., 2011). However, in the uranyl-ferrous iron system it is difficult to attribute

16 reduction solely to homogeneous pathways due to the complexities introduced by the generation of solid

17 redox products and transition to heterogeneous redox pathways. Aqueous analyses and interpretation of

18 the mechanisms controlling uranyl removal from solution becomes complicated, as loss of uranyl could

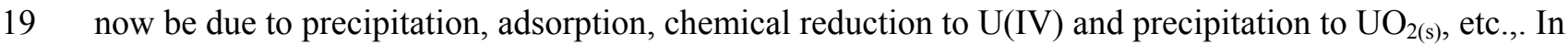

20 addition to analyzing the rate of uranyl removed from solution, it is necessary to apply a combination of

21 different methods to determine the removal mechanisms.

To attribute the removal of uranyl from solution by reduction, identification of the solid redox products and physical evidence of U(IV) is needed for confirmation of chemical reduction occurring (Noubactep, 2009). In this study, correlating aqueous data to uranyl reduction leads to higher concentrations of uranyl being reduced ( $\sim 38 \%$ after 72 hours) though analysis of the solids show that $\mathrm{U}(\mathrm{VI})$ is the dominant oxidation state and that $\sim 25 \%$ of the uranyl is reduced to $\mathrm{U}(\mathrm{V}) / \mathrm{U}(\mathrm{IV})$ within the first hour. Partial reduction of the uranyl solid is likely reached due to the formation of a passivation layer of reduced uranyl-oxide on the surface of the (meta)schoepite, which would inhibit further chemical reduction of U(VI) within the bulk (Fredrickson et al., 2000; Duff et al., 2002) (Figure 1; Table 1;

30 Processes 7c, 8c). Additionally, based on the XPS data from this study, it is possible that a portion of the 31 reduced uranyl product is $\mathrm{U}(\mathrm{V})$; previous studies showed the existence of $\mathrm{U}(\mathrm{V})$ over $\mathrm{U}(\mathrm{IV})$ could be due 32 to coordination environments favoring U(V) (Ilton et al., 2006; Ilton et al., 2010; Ilton et al., 2012). Thus, more detailed analyses of the solid $U$ redox product provide insight into whether $U(V I)$ reduction to 
$\mathrm{U}(\mathrm{IV})$ is proceeding to completion, which isotherms do not always show, and in turn contribute to predicting the stability and solubility of the solid $\mathrm{U}$ phase.

In addition to solid $\mathrm{U}$ redox products formed, the co-precipitation of iron redox products adds to the complexity of the system and, more importantly, impacts the energetics of uranyl reduction. Felmy et al., (2011) calculated the thermodynamics for the reduction of U(VI) by Fe(II) to assess the impact of different $\mathrm{Fe}(\mathrm{III})$ reaction products (using conditions from Liger et al., (1999)). Under these conditions, aqueous $\mathrm{Fe}(\mathrm{II})$ could only reduce aqueous $\mathrm{U}(\mathrm{VI})$ to $\mathrm{UO}_{2(\mathrm{am}, \mathrm{s})}$ at $\mathrm{pH}>8$. If stable $\mathrm{Fe}(\mathrm{III})$ reaction products form, the $\mathrm{pH}$ range over which $\mathrm{U}(\mathrm{VI})$ reduction can occur will increase. For instance, if hematite formed (via the overall reaction: $\mathrm{U}(\mathrm{VI})_{(\mathrm{aq})}+2 \mathrm{Fe}(\mathrm{II})_{(\mathrm{aq})} \leftrightarrow \mathrm{UO}_{2(\mathrm{am})}+\mathrm{Fe}_{2} \mathrm{O}_{3(\mathrm{~s})}$ ), it becomes thermodynamically possible to reduce $\mathrm{U}(\mathrm{VI})$ to $\mathrm{U}(\mathrm{IV})$ at $\mathrm{pH} \geq 6$. The type of $\mathrm{Fe}(\mathrm{III})$ reaction product formed (e.g., $\mathrm{FeOH}_{3(\mathrm{~s})}$ $\left.v s . \mathrm{Fe}_{2} \mathrm{O}_{3(\mathrm{~s})}\right)$ also has a large impact on the $\mathrm{pH}$ range over which the reaction occurs. Unfortunately, the $\mathrm{Fe}(\mathrm{III})$ reaction product(s) could not be determined in this study (with analysis requiring use of a combination of Mössbauer spectroscopy, TEM, XANES, and EXAFS) (Zachara et al., 2007; Peretyazhko et al., 2008). The free energy of the $\mathrm{Fe}(\mathrm{III})$ reaction products is a key factor in determining the range of conditions under which $\mathrm{U}(\mathrm{VI})$ can be reduced by $\mathrm{Fe}(\mathrm{II})$; future studies should emphasize characterizing the solid iron redox products to better understand its impact in redox environments.

\subsection{Conclusions}

A more fundamental understanding of mechanisms involved in the abiotic reduction of U(VI) by $\mathrm{Fe}(\mathrm{II})$ has been gained by combining experiments and ab initio modeling. Through careful monitoring and analysis of both the aqueous and solid fractions over time, experiments have clarified that U(VI) reduction by $\mathrm{Fe}(\mathrm{II})$ occurs in a heterogeneous system. Ab initio calculations reveal the nature of thermodynamic and kinetic barriers that must be overcome at the molecular scale in order for reduction to proceed in a homogeneous system, such as dehydration of solvated complexes and $\mathrm{Fe}^{2+}$ hydrolysis. In turn, reduction of $\mathrm{U}(\mathrm{VI})$ by $\mathrm{Fe}(\mathrm{II})$ in a homogeneous system is predicted to be kinetically inhibited. These atomistic details are difficult to observe using geochemical models or experiments, and have helped reinforce deductions from experiments. Our results not only show the reduction of soluble U(VI) by soluble $\mathrm{Fe}(\mathrm{II})$ to be thermodynamically and kinetically limited under the given experimental conditions, but also, and most importantly, shed light on the feasibility of uranyl reduction in a homogeneous system under different chemical conditions (e.g., in the presence of naturally occurring reductants such as sulfide 31 and hydroquinone). 
This study also helps provide insight into relevant redox mechanisms in analogous systems, such

2 as reduction on mineral surfaces. Reduction of U(VI) by Fe(II) was found to be thermodynamically

3 favorable and kinetically feasible for an IS complex. IS complexes are often observed for uranyl adsorbed

4 onto iron oxide surfaces (Waite et al., 1994; Sherman et al., 2008; Singh et al., 2012). Thus, it is possible

5 one of the atomistic mechanisms enabling reduction of uranyl in heterogeneous systems is the ability for

6 the mineral surface to strip solvating waters and facilitate the formation of an IS complex. More so, it is

7 of interest to understand whether minerals (particularly semiconducting minerals like hematite) directly

8 participate in redox processes. Semiconducting minerals are hypothesized to provide a structural template

9 that increases the probability of forming configurations compatible with ET/PCET and/or can serve as a

10 conduit for shuttling electron density from donor to acceptor. It is well established that semiconducting

11 minerals possess the ability to connect redox reactions at a distance, where an electron from a reductant at

12 one site of the mineral surface can be transferred through the mineral and reaches an oxidant within close

13 proximity (Becker et al., 2001; Rosso and Becker, 2003; Renock and Becker, 2010). The effect of the

14 mineral surface on the thermodynamics and kinetics for ET would again be important in predicting uranyl

15 mobility and reactivity, and is currently being investigated.

An in-depth understanding of the conditions conducive for abiotic reduction of U(VI) by Fe(II) is

17 required to accurately predict uranyl's mobility and reactivity. These conditions are a complex function of

18 chemical speciation and solubility, molecular-scale reaction mechanisms, and the thermodynamics,

19 kinetics, and reduction potential of uranyl in solution or sorbed onto geologic materials. For example, it

20 has been shown that predictions for the field-scale behavior of radionuclides at the Hanford site were

21 significantly improved in several transport models using in-depth atomistic and molecular-scale

22 characterization (Felmy et al., 2011). Thus, to most accurately predict the migration of radionuclides and

23 metals for realistic systems, integration of detailed experimental and computational results into

24 conceptual models is needed. The methodology used in this study, combining experimental and

25 computational approaches, has broad applications and will be applied in future studies to provide insight

26 into redox reaction pathways and mechanisms for other redox-sensitive systems. 


\section{Acknowledgements}

This research was supported by the U.S. Office of Science, BES/HEC (Basic Energy Sciences,

3 Heavy Element Chemistry) DE-FG02-06ER15783. The authors would like to thank the following

4 scientists for their technical assistance with the instrumentation used in this study: Dr. Thomas Yavaraski

5 (ICP-MS), Dr. Zhongrui Li (XRD), Ke Yuan (SEM; instrumentation supported primarily by DOD-G-

6 F49620-93-1-0289, Center for Advanced Structural Metallic Materials), and Dr. Eugene Ilton, Dr. Kai

7 Sun, and Dr. Haiping Sun (XPS; instrumentation supported by NSF grant \# DMR-0420785). We would

8 like to further thank Dr. Eugene Ilton for his help with XPS analyses and revisions of this manuscript. We

9 would also like to thank Dr. Drew Latta and Odeta Qafoku for their help with developing experimental

10 procedures. KMR acknowledges support from the Geosciences Program at Pacific Northwest National

11 Laboratory (PNNL) from the U.S. Department of Energy (DOE) Office of Science, Office of Basic

12 Energy Sciences, Division of Chemical Sciences, Geosciences, and Biosciences. A portion of the research

13 was performed using EMSL, a DOE Office of Science User Facility sponsored by the DOE Office of

14 Biological and Environmental Research and located at PNNL. 


\section{References}

Allen G.C., Crofts J.A., Curtis M.T., Tucker P.M., Chadwick D., and Hampson P.J. (1974). X-ray photoelectron-spectroscopy of some uranium oxide phases. J. Chem. Soc. Dalton, 1296-1301.

Becker U., Rosso K.M., and Hochella M.F. (2001). The proximity effect on semiconducting mineral surfaces: A new aspect of mineral surface reactivity and surface complexation theory? Geochim. Cosmochim. Acta 65, 2641-2649.

Charlet L., Bosbach D., and Peretyashko T. (2002). Natural attenuation of TCE, As, Hg linked to the heterogenenous oxidation of Fe(II): An AFM study. Chem. Geol. 190, 303-319.

Charlet L., Silvester E., and Liger E. (1998). N-compound reduction and actinide immobilisation in surficial fluids by $\mathrm{Fe}(\mathrm{II})$ : The surface $\equiv \mathrm{Fe}^{\mathrm{III}} \mathrm{OFe}^{\mathrm{II}} \mathrm{OH}^{0}$ species, as major reductant. Chem. Geol. 151, 85-93.

Delley B. (2006). The COnductor-like Screening MOdel for polymers and surfaces. Mol. Sim. 32, 117123.

Dolg M., Stoll H., Preuss H., and Pitzer R.M. (1993). Relativistic and correlation-effects for element 105 (Hahnium, Ha) - A comparative-study of $\mathrm{M}$ and $\mathrm{Mo}(\mathrm{M}=\mathrm{Nb}, \mathrm{Ta}, \mathrm{Ha})$ using energy-adjusted $a b$ initio pseudopotentials. $J$ Phys Chem-Us 97, 5852-5859.

Du X., Boonchayaanant B., Wu W.M., Fendorf S., Bargar J., and Criddle C.S. (2011). Reduction of uranium(VI) by soluble iron(II) conforms with thermodynamic predictions. Environ. Sci. Technol. 45, 4718-4725.

Duff M.C., Coughlin J.U., and Hunter D.B. (2002). Uranium co-precipitation with iron oxide minerals. Geochim. Cosmochim. Acta 66, 3533-3547.

Eary L.E. and Rai D. (1988). Chromate removal from aqueous wastes by reduction with ferrous iron. Environ. Sci. Technol. 22, 972-977.

EPA (2000). National primary drinking water regulations; radio-nuclides; final rule, in: Register, F. (Ed.), 236.

Farazdel A., Dupuis M., Clementi E., and Aviram A. (1990). Electric-field induced intramolecular electron-transfer in spiro pi-electron systems and their suitability as molecular electronic devices A theoretical-study. J. Am. Chem. Soc. 112, 4206-4214.

Felmy A.R., Ilton E.S., Rosso K.M., and Zachara J.M. (2011). Interfacial reactivity of radionuclides: Emerging paradigms from molecular-level observations. Min. Mag. 75, 2379-2391.

Fredrickson J.K., Zachara J.M., Kennedy D.W., Duff M.C., Gorby Y.A., Li S.-M.W., and Krupka K.M. (2000). Reduction of $\mathrm{U}(\mathrm{VI})$ in goethite $(\alpha-\mathrm{FeOOH})$ suspensions by a dissimilatory metal-reducing bacterium. Geochim. Cosmochim. Acta 64, 3085-3098.

Gabriel U., Gaudet J.P., Spadini L., and Charlet L. (1998). Reactive transport of uranyl in a goethite column: An experimental and modelling study. Chem. Geol. 151, 107-128.

Gustafsson J.P.(2010). Visual minteq v. 3.0.

Halgren T.A., and Lipscomb W.N. (1977). Synchronous-transit method for determining reaction pathways and locating molecular transition-states. Chem. Phys. Lett. 49, 225-232.

Harihara P.C. and Pople J.A. (1973). Influence of polarization functions on molecular-orbital hydrogenation energies. Theor. Chim. Acta 28, 213-222.

Hochella M.F. (1988). Auger-electron and x-ray photoelectron spectroscopies, Rev. Mineral., pp. 573637.

Hua B. and Deng B.L. (2008). Reductive immobilization of uranium(VI) by amorphous iron sulfide. Environ. Sci. Technol. 42, 8703-8708.

Hua B., Xu H.F., Terry J., and Deng B.L. (2006). Kinetics of uranium(VI) reduction by hydrogen sulfide in anoxic aqueous systems. Environ. Sci. Technol. 40, 4666-4671.

Ilton E.S. and Bagus P.S. (2011). XPS determination of uranium oxidation states. Surf. Int. Anal. 43, 1549-1560. 
Ilton E.S., Boily J.F., Buck E.C., Skomurski F.N., Rosso K.M., Cahill C.L., Bargar J.R., and Felmy A.R. (2010). Influence of dynamical conditions on the reduction of U-VI at the magnetite-solution interface. Environ. Sci. Technol. 44, 170-176.

Ilton E.S., Heald S.M., Smith S.C., Elbert D., and Liu C.X. (2006). Reduction of uranyl in the interlayer region of low iron micas under anoxic and aerobic conditions. Environ. Sci. Technol. 40, 50035009.

Ilton E.S., Pacheco J.S.L., Bargar J.R., Shi Z., Liu J., Kovarik L., Engelhard M.H., and Felmy A.R. (2012). Reduction of U(VI) incorporated in the structure of hematite. Environ. Sci. Technol. 46, 9428-9436.

Iordanova N., Dupuis M., and Rosso K.M. (2005). Charge transport in metal oxides: A theoretical study of hematite $\alpha-\mathrm{Fe}_{2} \mathrm{O}_{3}$. J. Chem. Phys. 122.

Jang J.-H., Dempsey B.A., and Burgos W.D. (2006). Solubility of schoepite: Comparison and selection of complexation constants for U(VI). Water Res. 40, 2738-2746.

Kerisit S., and Rosso K.M. (2006). Computer simulation of electron transfer at hematite surfaces. Geochim. Cosmochim. Acta 70, 1888-1903.

Klamt A. and Schuurmann G. (1993). COSMO - A new approach to dielectric screening in solvents with explicit expressions for the screening energy and its gradient. J. Chem. Soc. Perk. T. 2, 799-805.

Küchle W., Dolg M., Stoll H., and Preuss H. (1991). Ab initio pseudopotentials for Hg through Rn. I. Parameter sets and atomic calculations. Mol. Phys. 74, 1245-1263.

Liger E., Charlet L., and Van Cappellen P. (1999). Surface catalysis of uranium(VI) reduction by iron(II). Geochim. Cosmochim. Acta 63, 2939-2955.

Marcus R.A. (1993). Electron transfer reactions in chemistry: Theory and experiment (nobel lecture). Angewandte Chemie International Edition in English 32, 1111-1222.

Marcus R.A. and Sutin N. (1985). Electron transfers in chemistry and biology. Biochim. Biophys. Acta 811, 265-322.

Morel F.M.M. and Hering J.G., (1993). Principles and applications of aquatic chemistry. John Wiley \& Sons, Inc., New York, NY.

Noubactep C. (2009). Comment on "Reductive immobilization of uranium(VI) by amorphous iron sulfide". Environ. Sci. Technol. 43, 1236-1236.

Peretyazhko T., Zachara J.M., Heald S.M., Jeon B.H., Kukkadapu R.K., Liu C., Moore D., and Resch C.T. (2008). Heterogeneous reduction of Tc(VII) by Fe(II) at the solid-water interface. Geochim. Cosmochim. Acta 72, 1521-1539.

Renock D. and Becker U. (2010). A first principles study of the oxidation energetic and kinetics of realgar. Geochim. Cosmochim. Acta 74, 4266-4284.

Rosso K.M., and Becker U. (2003). Proximity effects on semiconducting mineral surfaces II: Distance dependence of indirect interactions. Geochim. Cosmochim. Acta 67, 941-953.

Rosso K.M. and Dupuis M. (2006). Electron transfer in environmental systems: A frontier for theoretical chemistry. Theor. Chem. Acc. 116, 124-136.

Rosso K.M. and Morgan J.J. (2002). Outer-sphere electron transfer kinetics of metal ion oxidation by molecular oxygen. Geochim. Cosmochim. Acta 66, 4223-4233.

Rosso K.M., Smith D.M.A., and Dupuis M. (2003). An ab initio model of electron transport in hematite $\left(\alpha-\mathrm{Fe}_{2} \mathrm{O}_{3}\right)$ basal planes. J. Chem. Phys. 118, 6455-6466.

Rosso K.M., Smith D.M.A., and Dupuis M. (2004). Aspects of aqueous iron and manganese (II/III) selfexchange electron transfer reactions. J. Phys. Chem. A 108, 5242-5248.

Schafer A., Horn H., and Ahlrichs R. (1992). Fully optimized contracted gaussian-basis sets for atoms Li to Kr. J. Chem. Phys. 97, 2571-2577.

Schindler P.W. (1991). A solution chemists view of surface-chemistry. Pure Appl. Chem. 63, 1697-1704.

Sherman D.M., Peacock C.L., and Hubbard C.G. (2008). Surface complexation of U(VI) on goethite $(\alpha-$ FeOOH). Geochim. Cosmochim. Acta 72, 298-310.

Singh A., Catalano J.G., Ulrich K.U., and Giammar D.E. (2012). Molecular-scale structure of uranium(VI) immobilized with goethite and phosphate. Environ. Sci. Technol. 46, 6594-6603. 
Skomurski F.N., Ilton E.S., Engelhard M.H., Arey B.W., and Rosso K.M. (2011). Heterogeneous reduction of $\mathrm{U}^{6+}$ by structural $\mathrm{Fe}^{2+}$ from theory and experiment. Geochim. Cosmochim. Acta 75 , 7277-7290.

Valiev M., Bylaska E.J., Govind N., Kowalski K., Straatsma T.P., Van Dam H.J.J., Wang D., Nieplocha J., Apra E., Windus T.L., and de Jong W. (2010). NWChem: A comprehensive and scalable opensource solution for large scale molecular simulations. Comput. Phys. Commun. 181, 1477-1489.

Waite T.D., Davis J.A., Payne T.E., Waychunas G.A., and Xu N. (1994). Uranium(VI) adsorption to ferrihydrite: Application of a surface complexation model. Geochim. Cosmochim. Acta 58, 54655478.

Wander M.C.F., Kerisit S., Rosso K.M., and Schoonen M.A.A. (2006). Kinetics of triscarbonato uranyl reduction by aqueous ferrous iron: A theoretical study. J. Phys. Chem. A 110, 9691-9701.

Wander M.C.F. and Schoonen M.A.A. (2010). Green rust reduction of chromium part 2: Comparison of heterogeneous and homogeneous chromate reduction. J. Phys. Chem. C 114, 16408-16415.

Wehrli B., Sulzberger B., and Stumm W. (1989). Redox processes catalyzed by hydrous oxide surfaces. Chem. Geol. 78, 167-179.

Wersin P., Hochella M.F., Persson P., Redden G., Leckie J.O., and Harris D.W. (1994). Interaction between aqueous uranium(VI) and sulfide minerals - Spectroscopic evidence for sorption and reduction. Geochim. Cosmochim. Acta 58, 2829-2843.

Zachara J.M., Heald S.M., Jeon B.H., Kukkadapu R.K., Liu C.X., McKinley J.P., Dohnalkova A.C., and Moore D.A. (2007). Reduction of pertechnetate [Tc(VII)] by aqueous Fe(II) and the nature of solid phase redox products. Geochim. Cosmochim. Acta 71, 2137-2157.

Zeng H. and Giammar D.E. (2011). U(VI) reduction by Fe(II) on hematite nanoparticles. J. Nanopart. Res. 13, 3741-3754. 


\section{Table Captions}

Table 1. Description of possible behaviors for $\mathrm{U}$ and $\mathrm{Fe}$ in homogeneous systems, relevant to this study, as shown in Figure 1.

Table 2. Proportion of reduced U over time from XPS quantification.

Table 3. Measured atomic distances for Fe and U cations for the outer-sphere (OS) and inner-sphere (IS) models.

Table 4. Calculated thermodynamic and kinetic properties for the OS and IS models. *Denotes reactions that are adiabatic. **Denotes properties determined using data fit to PT values. 


\section{Figure captions for grayscale images}

Figure 1: Potential processes occurring in a homogenous system between uranyl and ferrous iron, including processes leading to the transition towards a heterogeneous system. The thick arrows denote processes where ET is occurring.

Figure 2: (a) Aqueous chemical speciation for $1 \mathrm{mM} \mathrm{Fe(II)} \mathrm{(in} \mathrm{the} \mathrm{presence} \mathrm{of} 0.16 \mathrm{mM} \mathrm{U}(\mathrm{VI})$ ) at experimental conditions ( $50 \mathrm{mM} \mathrm{NaCl}, 5 \mathrm{mM}$ HEPES, $p \mathrm{H}_{2}=0.05$ atm, $p \mathrm{~N}_{2}=0.95 \mathrm{~atm}$ ). (b) Aqueous chemical speciation for $0.16 \mathrm{mM} \mathrm{U}(\mathrm{VI})$ (in the presence of $1 \mathrm{mM} \mathrm{Fe}^{2+}$ ) at experimental conditions.

Figure 3: Free energy diagram of an electron transfer reaction. Modified from Kerisit et al., (2006).

Figure 4: (a) Aqueous uranium concentrations over time comparing measurements from Experiments 1 (open circle) and 2 (open triangle). The initial U(VI) concentration for Experiment 1 is $0.16 \mathrm{mM}$, and is not shown on the figure in order to observe changes at lower concentrations in better detail. (b) Aqueous Fe(II) concentrations over time comparing measurements from Experiments 1 (filled circle) and 2 (filled triangle). (c) Comparison between relative uranyl and ferrous iron concentrations over time for both the Experiment 1and 2. Circle markers denote data from Experiment 1 while triangle markers denote data from Experiment 2. Open markers denote aqueous $U$ concentrations for the respective experiments while filled markers denote aqueous Fe concentrations. (d) Correlation between $\mathrm{U}$ and Fe concentrations over time for Experiment 1. Markers are circles that half-filled and half-unfilled to denote the comparison between $\mathrm{Fe}$ and $\mathrm{U}$ concentrations.

Figure 5: XRD pattern for the $0.17 \mathrm{mM} \mathrm{U}(\mathrm{VI})$ control experiment and comparison with peak lists to other uranyl solids phases; the PDF-\#s for the solids are 01-086-1383 (schoepite), 01-089-7333 (metaschoepite), and 01-074-1468 ( $\left.\beta-\mathrm{UO}_{2}(\mathrm{OH})_{2}\right)$.

Figure 6: Saturation index for uranyl and ferrous iron solids at the experimental conditions used (0.16 $\mathrm{mM} \mathrm{UO}_{2}{ }^{2+}, 1 \mathrm{mM} \mathrm{Fe}^{2+}, 50 \mathrm{mM} \mathrm{NaCl}, 5 \mathrm{mM}$ HEPES, $\left.p \mathrm{H}_{2}=0.05 \mathrm{~atm}, p \mathrm{~N}_{2}=0.95 \mathrm{~atm}\right)$.

Figure 7: (a) U 4f XPS spectra for solids representing different times of the Experiment 1, overlain together for comparison. (b) Fitted GL curves for U4f 7/2 peak at 0.75 hours from Experiment 1, as an example of how proportions of $U(V I)$ and reduced uranyl were quantified. (c) $U$ ff spectra for solids representing different times of the Experiment 2, overlain together for comparison. 
Figure 8: (a) BSE image and EDS spectra for filtered $0.02 \mathrm{mM} \mathrm{UO}_{2}{ }^{2+}$ solution obtained at 3 hours, showing the absence of precipitates at the early stages of the experiment. (b) BSE image and EDS spectra for filtered $0.02 \mathrm{mM} \mathrm{UO}_{2}{ }^{2+}$ solution obtained at 24 hours, showing the presence of uranium-oxide precipitates. The $0-8 \mathrm{keV}$ energy region was chosen for analysis of the 24 hour sample to better resolve elemental information.

Figure 9: Trends in the free energies of U-Fe redox reactions as a function of aqueous and/or solid products generated. The markers indicate the aqueous reactants used in the calculation.

Figure 10: DFT geometry optimized pre-ET (a) and post-ET (b) states for the OS models, where water ligands separate $\mathrm{Fe}-\mathrm{U}$ complexes. The values next to the $\mathrm{Fe}$ and $\mathrm{U}$ cations indicate the Mulliken spins for that ET state. Circled hydrogen atoms denote occurrences of PT. (c) PE surface for the ferrimagnetic, $\mathrm{PCET}_{\text {conc }}$ reaction; solid data points are calculated values while the solid lines are the curves fitted to the properly calculated data points. Reaction coordinate 0 represents the pre-ET state and 1 represents the post-ET state. (d) PE surface for the ferrimagnetic, PCET $_{\text {seq }}$ reaction; makers are calculated values while the solid and dashed lines are the parabolas fitted to the calculated values. The solid lines are parabolas fit to the ET step (i.e., the coefficient $a$ is the same for each curve); the dashed curve indicates parabolas fit to the PT data values, yielding higher reorganization energies. Reaction coordinate 0 represents the preET state; 1 the intermediate state; and 2 the post-ET state.

Figure 11: DFT geometry optimized pre-ET (a) and post-ET (b) states for the IS models, where Fe-U complexes are connected by bridging-hydroxyl ligands. The values next to the Fe and U cations indicate the Mulliken spins for that ET state. (c) PE surface for the ferrimagnetic ET reaction; solid data points are calculated values while the solid lines are the curves fitted to the properly calculated data points (the coefficient $a$ is the same for each curve). 


\section{Figure captions for color images}

Figure 2: Potential processes occurring in a homogenous system between uranyl and ferrous iron, including processes leading to the transition towards a heterogeneous system. The red arrows denote processes where ET is occurring.

Figure 2: (a) Aqueous chemical speciation for $1 \mathrm{mM} \mathrm{Fe(II)} \mathrm{(in} \mathrm{the} \mathrm{presence} \mathrm{of} 0.16 \mathrm{mM} \mathrm{U}(\mathrm{VI})$ ) at experimental conditions ( $50 \mathrm{mM} \mathrm{NaCl}, 5 \mathrm{mM}$ HEPES, $p \mathrm{H}_{2}=0.05$ atm, $p \mathrm{~N}_{2}=0.95 \mathrm{~atm}$ ). (b) Aqueous chemical speciation for $0.16 \mathrm{mM} \mathrm{U}(\mathrm{VI})$ (in the presence of $1 \mathrm{mM} \mathrm{Fe}^{2+}$ ) at experimental conditions.

Figure 3: Free energy diagram of an electron transfer reaction. Modified from Kerisit et al., (2006).

Figure 4: (a) Aqueous uranium concentrations over time comparing measurements from Experiments 1 (open, red circle) and 2 (open, red triangle). The initial U(VI) concentration for Experiment 1 is $0.16 \mathrm{mM}$, and is not shown on the figure in order to observe changes at lower concentrations in better detail. (b) Aqueous Fe(II) concentrations over time comparing measurements from Experiments 1 (filled, green circle) and 2 (filled, green triangle). (c) Comparison between relative uranyl and ferrous iron concentrations over time for both the Experiment 1and 2. Circle markers denote data from Experiment 1 while triangle markers denote data from Experiment 2. Open, red markers denote aqueous $U$ concentrations for the respective experiments while filled, green markers denote aqueous $\mathrm{Fe}$ concentrations. (d) Correlation between $\mathrm{U}$ and Fe concentrations over time for Experiment 1. Markers are filled with green and red to denote the comparison between $\mathrm{Fe}$ and $\mathrm{U}$ concentrations.

Figure 5: XRD pattern for the $0.17 \mathrm{mM} \mathrm{U}(\mathrm{VI})$ control experiment and comparison with peak lists to other uranyl solids phases; the PDF-\#s for the solids are 01-086-1383 (schoepite), 01-089-7333 (metaschoepite), and 01-074-1468 ( $\left.\beta-\mathrm{UO}_{2}(\mathrm{OH})_{2}\right)$.

Figure 6: Saturation index for uranyl (red lines) and ferrous iron solids (green lines) at the experimental conditions used $\left(0.16 \mathrm{mM} \mathrm{UO}_{2}{ }^{2+}, 1 \mathrm{mM} \mathrm{Fe}^{2+}, 50 \mathrm{mM} \mathrm{NaCl}, 5 \mathrm{mM}\right.$ HEPES, $p \mathrm{H}_{2}=0.05 \mathrm{~atm}, p \mathrm{~N}_{2}=0.95$ atm).

Figure 7: (a) U 4f XPS spectra for solids representing different times of the Experiment 1, overlain together for comparison. (b) Fitted GL curves for U4f 7/2 peak at 0.75 hours from Experiment 1, as an example of how proportions of U(VI) and reduced uranyl were quantified. (c) $U$ 4f spectra for solids representing different times of the Experiment 2, overlain together for comparison. 
Figure 8: (a) BSE image and EDS spectra for filtered $0.02 \mathrm{mM} \mathrm{UO}_{2}{ }^{2+}$ solution obtained at 3 hours, showing the absence of precipitates at the early stages of the experiment. (b) BSE image and EDS spectra for filtered $0.02 \mathrm{mM} \mathrm{UO}_{2}{ }^{2+}$ solution obtained at 24 hours, showing the presence of uranium-oxide precipitates. The $0-8 \mathrm{keV}$ energy region was chosen for analysis of the 24 hour sample to better resolve elemental information.

Figure 9: Trends in the free energies of U-Fe redox reactions as a function of aqueous and/or solid products generated. The markers indicate the aqueous reactants used in the calculation.

Figure 10: DFT geometry optimized pre-ET (a) and post-ET (b) states for the OS models, where water ligands separate $\mathrm{Fe}-\mathrm{U}$ complexes. The values next to the $\mathrm{Fe}$ and $\mathrm{U}$ cations indicate the Mulliken spins for that ET state. Circled hydrogen atoms denote occurrences of PT. (c) PE surface for the ferrimagnetic, $\mathrm{PCET}_{\text {conc }}$ reaction; solid data points are calculated values while the solid lines are the curves fitted to the properly calculated data points. Reaction coordinate 0 represents the pre-ET state and 1 represents the post-ET state. (d) PE surface for the ferrimagnetic, PCET $_{\text {seq }}$ reaction; makers are calculated values while the solid and dashed lines are the parabolas fitted to the calculated values. The solid lines are parabolas fit to the ET step (i.e., the coefficient $a$ is the same for each curve); the dashed curve indicates parabolas fit to the PT data values, yielding higher reorganization energies. Reaction coordinate 0 represents the preET state; 1 the intermediate state; and 2 the post-ET state.

Figure 11: DFT geometry optimized pre-ET (a) and post-ET (b) states for the IS models, where Fe-U complexes are connected by bridging-hydroxyl ligands. The values next to the Fe and U cations indicate the Mulliken spins for that ET state. (c) PE surface for the ferrimagnetic ET reaction; solid data points are calculated values while the solid lines are the curves fitted to the properly calculated data points (the coefficient $a$ is the same for each curve). 


\section{Equations}

$$
\begin{aligned}
& p e=p e^{0}-\log \frac{[\text { Reductant }]}{[\text { Oxidant }]} \\
& \Delta G=-n \times 2.3 R T\left(p e_{1}-2 \times p e_{2}\right) \\
& P_{12}=1-\exp \left(\left(-\frac{V_{A B}^{2}}{h v}\right) \sqrt{\frac{\pi^{3}}{\lambda k_{B} T}}\right) \\
& \Delta G^{*}=\frac{\left(\lambda+\Delta G^{0}\right)^{2}}{4 \lambda}-V_{A B} \\
& k_{E T}=v e^{\frac{-\Delta G^{*}}{k_{B} T}}
\end{aligned}
$$

$$
k_{E T}=\frac{2 \pi}{\hbar}\left|V_{A B}\right|^{2} \frac{1}{\sqrt{4 \pi \lambda k_{B} T}} \exp \left(-\frac{\left(\Delta G^{0}+\lambda\right)^{2}}{4 \pi \lambda k_{B} T}\right)
$$

$$
\begin{aligned}
& \mathrm{Fe}\left(\mathrm{H}_{2} \mathrm{O}\right)_{6}^{2+}-\mathrm{UO}_{2}(\mathrm{OH})_{2}\left(\mathrm{H}_{2} \mathrm{O}\right)_{2} \leftrightarrow\left(\left(\mathrm{H}_{2} \mathrm{O}\right)_{4} \mathrm{Fe}(\mathrm{OH})_{2}-\mathrm{UO}_{2}\left(\mathrm{H}_{2} \mathrm{O}\right)_{2}\right)^{2+}+2 \mathrm{H}_{2} \mathrm{O} \\
& 2 \mathrm{Fe}^{2+}+\frac{1}{3}\left(\mathrm{UO}_{2}\right)_{3}(\mathrm{OH})_{5}^{+}+\frac{13}{3} \mathrm{H}_{2} \mathrm{O} \rightarrow 2 \mathrm{Fe}(\mathrm{OH})_{2}^{+}+\mathrm{U}(\mathrm{OH})_{4}+\frac{7}{3} \mathrm{H}^{+} \Delta \mathrm{G}=+161 \mathrm{~kJ} / \mathrm{mol}
\end{aligned}
$$

$$
2 \mathrm{Fe}^{2+}+\frac{1}{3}\left(\mathrm{UO}_{2}\right)_{3}(\mathrm{OH})_{5}^{+}+\frac{19}{3} \mathrm{H}_{2} \mathrm{O} \rightarrow 2 \mathrm{Fe}(\mathrm{OH})_{3(s)}+\mathrm{U}(\mathrm{OH})_{4}+\frac{13}{3} \mathrm{H}^{+} \quad \Delta \mathrm{G}=+19 \mathrm{~kJ} / \mathrm{mol}
$$

$$
2 \mathrm{Fe}^{2+}+\frac{1}{3}\left(\mathrm{UO}_{2}\right)_{3}(\mathrm{OH})_{5}^{+}+\frac{10}{3} \mathrm{H}_{2} \mathrm{O} \rightarrow \mathrm{Fe}_{2} \mathrm{O}_{3(s)}+\mathrm{U}(\mathrm{OH})_{4}+\frac{13}{3} \mathrm{H}^{+} \quad \Delta \mathrm{G}=-46 \mathrm{~kJ} / \mathrm{mol}
$$


Table 1

\begin{tabular}{|c|c|c|}
\hline & Behavior & General factors influencing proposed behavior \\
\hline 1 & $\begin{array}{l}\text { Aqueous U(VI) and } \\
\mathrm{Fe}(\mathrm{II})\end{array}$ & $\begin{array}{l}\text { Concentrations below solubility limits }\left(\log { }^{*} \mathrm{~K}_{\mathrm{sp}, \mathrm{U}(\mathrm{VI})-}\right. \\
\left.\text { hydroxides }=[4.9,7.7] ; \log ^{*} \mathrm{~K}_{\mathrm{sp}, \mathrm{Fe}(\mathrm{II})-\text { hydroxides }}=[12.9,13.5]\right) \text { at } \\
\text { appropriate conditions }(\text { e.g., } \mathrm{pH})(\mathrm{Jang} \text { et al., } 2006 ; \text { Gustafsson, } \\
\text { 2010) }\end{array}$ \\
\hline $2 \mathrm{a}$ & $\begin{array}{l}\text { Complexes between } \\
\text { aqueous } \mathrm{Fe}(\mathrm{II}) \text { and U(VI) }\end{array}$ & Limited experimental data \\
\hline $2 \mathrm{~b}$ & $\begin{array}{l}\text { Reduction of U(VI) by } \\
\text { Fe(II) in aqueous } \\
\text { complexation }\end{array}$ & $\begin{array}{l}\text { Theoretical studies show dependence on thermodynamics, } \\
\text { kinetics, complexing ligands, outer- vs. inner-sphere } \\
\text { coordination, etc., (Privalov et al., 2003; Wander et al., 2006) }\end{array}$ \\
\hline 3 & Precipitation of U(VI) & $\begin{array}{l}\text { Concentrations above solubility limits at appropriate conditions } \\
(\text { e.g., } \mathrm{pH}>4.5)\end{array}$ \\
\hline 4 & Precipitation of Fe(II) & Concentrations above solubility limits $(e . g ., \mathrm{pH}>7.5)$ \\
\hline $5 \mathrm{a}$ & $\begin{array}{l}\text { Oxidation of soluble } \\
\text { Fe(II) to Fe(III) }\end{array}$ & $\begin{array}{l}\text { Availability and reactivity of oxidant at appropriate conditions } \\
\text { (e.g., Eh-pH) }\end{array}$ \\
\hline $5 \mathrm{~b}$ & Precipitation of $\mathrm{Fe}(\mathrm{III})$ & $\begin{array}{l}\text { Above } \mathrm{Fe}(\mathrm{III}) \text { phase solubility products } \\
\left(\log { }^{*} \mathrm{~K}_{\mathrm{sp}, \mathrm{Fe}(\mathrm{II}) /(\mathrm{III})-(\mathrm{hydr}) \text { oxides }}=[-1.4,3.4]\right)(\text { Gustafsson, 2010) }\end{array}$ \\
\hline $6 \mathrm{a}$ & $\begin{array}{l}\text { Reduction of soluble } \\
\text { U(VI) to U(IV) }\end{array}$ & $\begin{array}{l}\text { Availability and reactivity of reductant (Du et al., 2011) at } \\
\text { appropriate conditions (e.g., Eh-pH) }\end{array}$ \\
\hline $6 \mathrm{~b}$ & Precipitation of U(IV) & $\begin{array}{l}\text { Above U(IV) phase solubility products }\left(\log { }^{*} \mathrm{~K}_{\mathrm{sp}, \mathrm{UO} 2}=-4.7\right) \\
(\text { Jang } \text { et al., 2006; Gustafsson, 2010) }\end{array}$ \\
\hline $7 \mathrm{a}$ & $\begin{array}{l}\text { Adsorption of } \mathrm{Fe}(\mathrm{II}) \text { on } \\
\text { solid uranyl phase }\end{array}$ & $\begin{array}{l}\text { Solids present (generated through processes such as } 3 \text { and } 6 \mathrm{~b}) \\
\text { with available surface sites, at appropriate solution conditions } \\
(\text { e.g., pH) }\end{array}$ \\
\hline $7 \mathrm{~b}$ & $\begin{array}{l}\text { ET between U(s) and } \\
\text { Fe(II) }\end{array}$ & Complexation such as in process 2 \\
\hline $7 \mathrm{c}$ & $\begin{array}{l}\text { Formation of passivation } \\
\text { layers on original } U(s)\end{array}$ & $\begin{array}{l}\text { Surface area saturated by redox products without new surface } \\
\text { area being exposed after reaction }\end{array}$ \\
\hline $8 \mathrm{a}$ & $\begin{array}{l}\text { Adsorption of U(VI) on } \\
\text { solid ferrous iron- } \\
\text { containing phase(s) }\end{array}$ & $\begin{array}{l}\text { Solids present (generated through processes such as } 4 \text { and } 5 \mathrm{~b} \text { ) } \\
\text { with available surface sites, at appropriate solution conditions } \\
(\text { e.g., pH) }\end{array}$ \\
\hline $8 \mathrm{~b}$ & $\begin{array}{l}\text { ET between } \mathrm{Fe}(\mathrm{s}) \text { and } \\
\mathrm{U}(\mathrm{VI})\end{array}$ & Complexation such as in process 2 \\
\hline $8 \mathrm{c}$ & $\begin{array}{l}\text { Formation of passivation } \\
\text { layers on original } \mathrm{Fe}(\mathrm{s})\end{array}$ & $\begin{array}{l}\text { Surface area saturated by redox products without new surface } \\
\text { area being exposed after reaction }\end{array}$ \\
\hline
\end{tabular}


Table 2

\begin{tabular}{|l|l|l|l|l|}
\hline \multirow{2}{*}{ Time (hour) } & \multicolumn{3}{|l|}{ Expt 1 } & \multicolumn{2}{l|}{ Expt 2 } \\
\cline { 2 - 5 } & $\begin{array}{l}\text { \% } \\
\text { U(VI) }\end{array}$ & $\begin{array}{l}\text { \% U } \\
\text { reduced }\end{array}$ & $\begin{array}{l}\text { \% } \\
\text { U(VI) }\end{array}$ & $\begin{array}{l}\text { \% U } \\
\text { reduced }\end{array}$ \\
\hline Schoepite standard & 99.4 & 0.6 & & \\
\hline 0.75 & 76.1 & 23.9 & NA & NA \\
\hline 3 & 75.1 & 24.9 & NA & NA \\
\hline 8 & 74.5 & 25.5 & NA & NA \\
\hline 24 & 74.3 & 25.7 & 65.1 & 34.9 \\
\hline 48 & 73.2 & 26.8 & 67.4 & 32.6 \\
\hline 72 & 73.8 & 26.2 & 66.6 & 33.4 \\
\hline
\end{tabular}

Table 3

\begin{tabular}{|l|l|l|l|l|}
\hline \multirow{2}{*}{$\begin{array}{l}\text { Average } \\
\text { distance }(\AA)\end{array}$} & \multicolumn{3}{|l|}{ Model } \\
\cline { 2 - 5 } & \multicolumn{2}{|l|}{ Outer-sphere } & \multicolumn{2}{l|}{ Inner-sphere } \\
\cline { 2 - 5 } & Pre-ET & Post-ET & Pre-ET & Post-ET \\
\hline $\mathrm{U}-O H_{\text {eq }}$ & 2.219 & NA & 2.288 & 2.56 \\
\hline $\mathrm{U}-\mathrm{OH}_{2, \text { eq }}$ & 2.532 & 2.519 & 2.505 & 2.514 \\
\hline $\mathrm{U}-\mathrm{O}_{\mathrm{ax}}$ & 1.769 & 1.803 & 1.752 & 1.795 \\
\hline $\mathrm{U}-\mathrm{Fe}$ & 4.831 & 4.811 & 3.412 & 3.455 \\
\hline $\mathrm{Fe}-\mathrm{OH}$ & NA & 1.875 & 2.105 & 1.896 \\
\hline $\mathrm{Fe}-\mathrm{OH}_{2}$ & 2.152 & 2.162 & 2.186 & 2.17 \\
\hline
\end{tabular}


Table 4

\begin{tabular}{|c|c|c|c|c|c|c|}
\hline $\begin{array}{c}\text { Model } \\
\text { (spin-configuration) }\end{array}$ & $\begin{array}{c}\Delta \mathbf{G}^{0} \\
(\mathbf{k J} / \mathbf{m o l})\end{array}$ & $\begin{array}{c}\lambda \\
(\mathbf{k J} / \mathbf{m o l})\end{array}$ & $\begin{array}{c}\Delta \mathbf{G}^{*} \\
(\mathbf{k J} / \mathbf{m o l})\end{array}$ & $\begin{array}{c}\mathrm{V}_{\mathrm{AB}} \\
(\mathrm{kJ} / \mathbf{m o l})\end{array}$ & $\mathbf{P}_{12}$ & $k_{E T}\left(s^{-1}\right)$ \\
\hline $\begin{array}{c}\text { OS PCET }_{\text {conc }} \\
\text { (ferromagnetic) }\end{array}$ & -19.395 & 769.105 & 192.348 & 9.928 & 0.963 & $9.892 \times 10^{-20} *$ \\
\hline $\begin{array}{l}\text { OS PCET }_{\text {conc }} \\
\text { (ferrimagnetic) }\end{array}$ & -35.403 & 707.345 & 176.809 & 1.349 & 0.061 & $3.760 \times 10^{-19}$ \\
\hline $\begin{array}{c}\text { OS PCET }_{\text {seq }} \\
\text { (ferrimagnetic, } \\
\text { ET without PT) }\end{array}$ & 102.113 & 209.984 & 117.138 & 0.193 & 0.002 & $3.111 \times 10^{-12}$ \\
\hline $\begin{array}{c}\text { OS PCET }_{\text {seq }} \\
\text { (ferrimagnetic, } \\
\text { ET with PT) }\end{array}$ & -134.421 & $\begin{array}{r}524.960 * *, \\
209.984)\end{array}$ & $\begin{array}{r}(83.994 * *, \\
8.399)\end{array}$ & $\begin{array}{r}(0.412 * * \\
0.167)\end{array}$ & $\begin{array}{r}(0.007 * *, \\
0.002)\end{array}$ & $\begin{array}{r}\left(1.750 \times 10^{-3} * *,\right. \\
\left.1.783 \times 10^{9}\right)\end{array}$ \\
\hline $\begin{array}{c}\text { IS } \\
\text { (ferromagnetic) }\end{array}$ & -16.202 & 186.245 & 37.774 & 0.624 & 0.026 & $2.056 \times 10^{4}$ \\
\hline $\begin{array}{c}\text { IS } \\
\text { (ferrimagnetic) }\end{array}$ & -16.376 & 174.558 & 33.493 & 9.8015 & 0.999 & $2.750 \times 10^{8} *$ \\
\hline
\end{tabular}




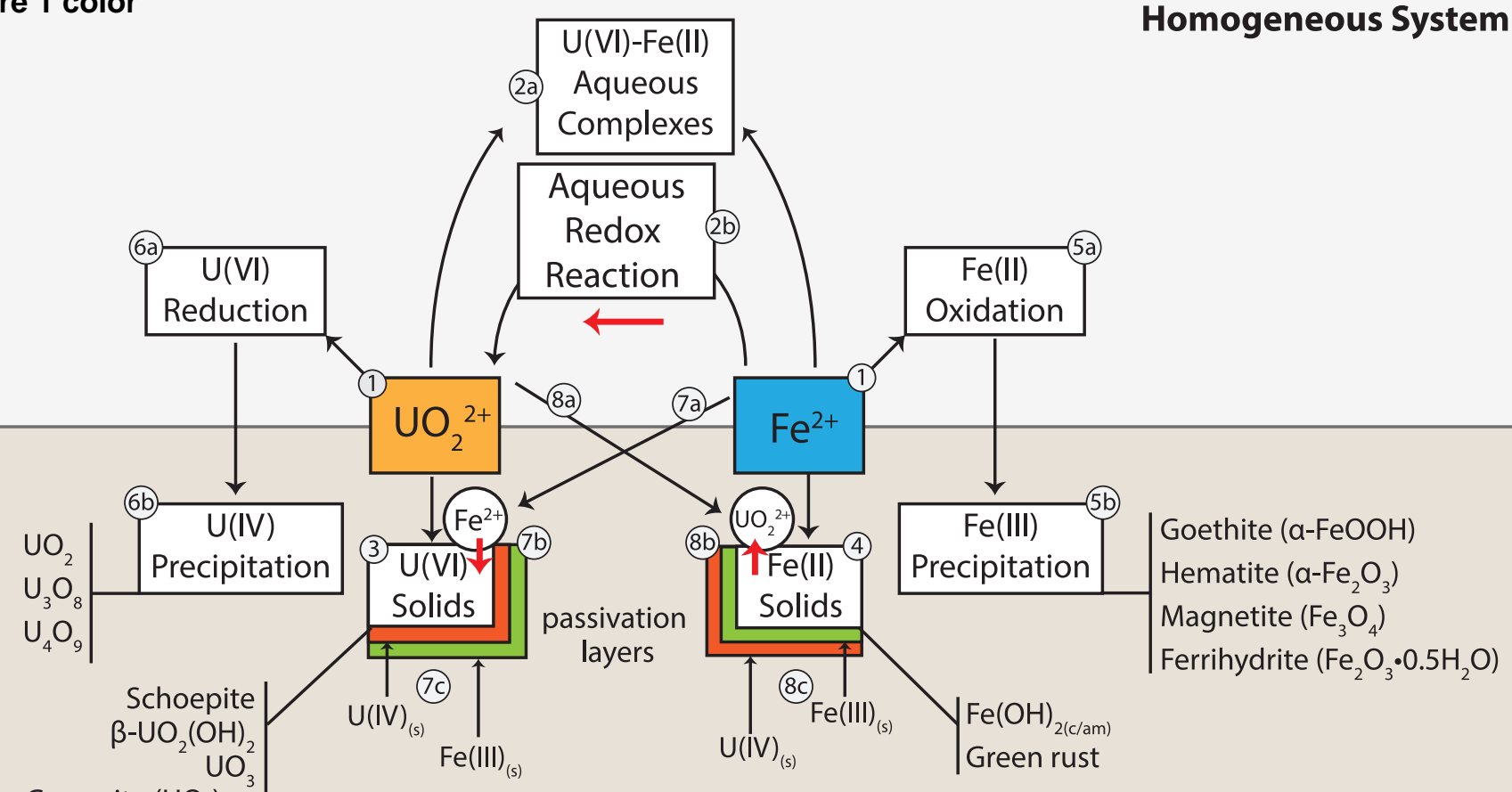

Gummite $\left(\mathrm{UO}_{3}\right)_{(\mathrm{am})}$ 

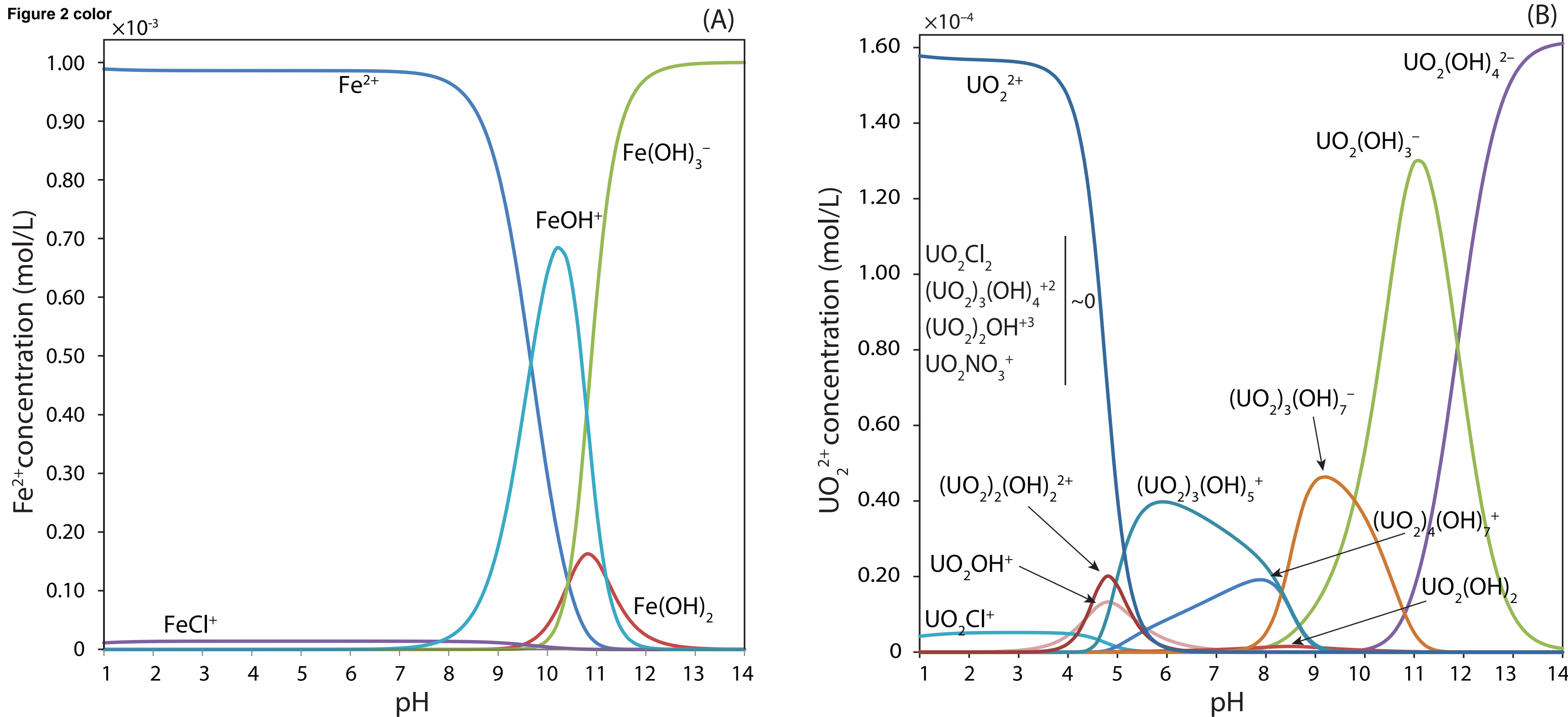
Figure 3 color

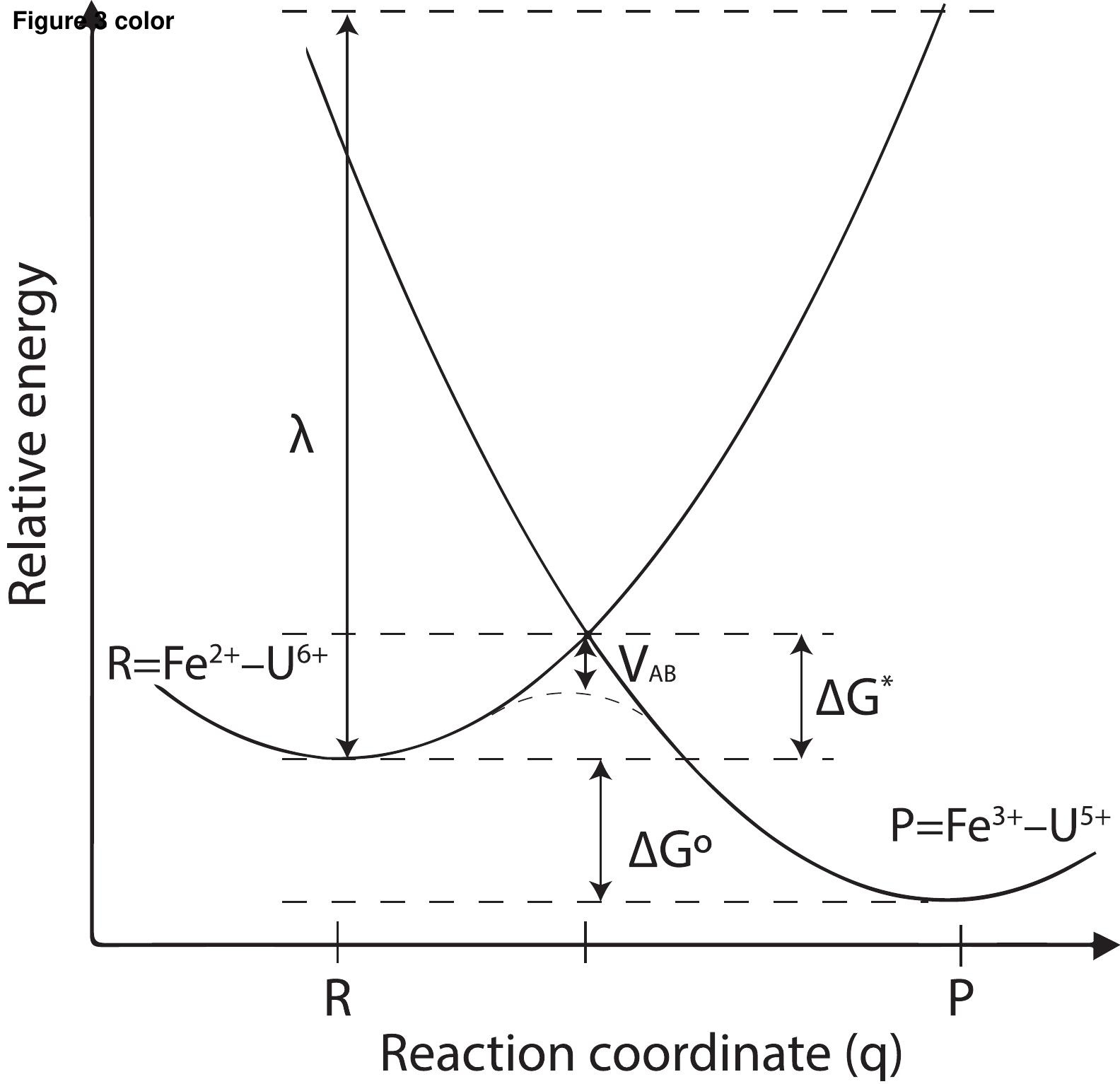


Figure 5 c.lob

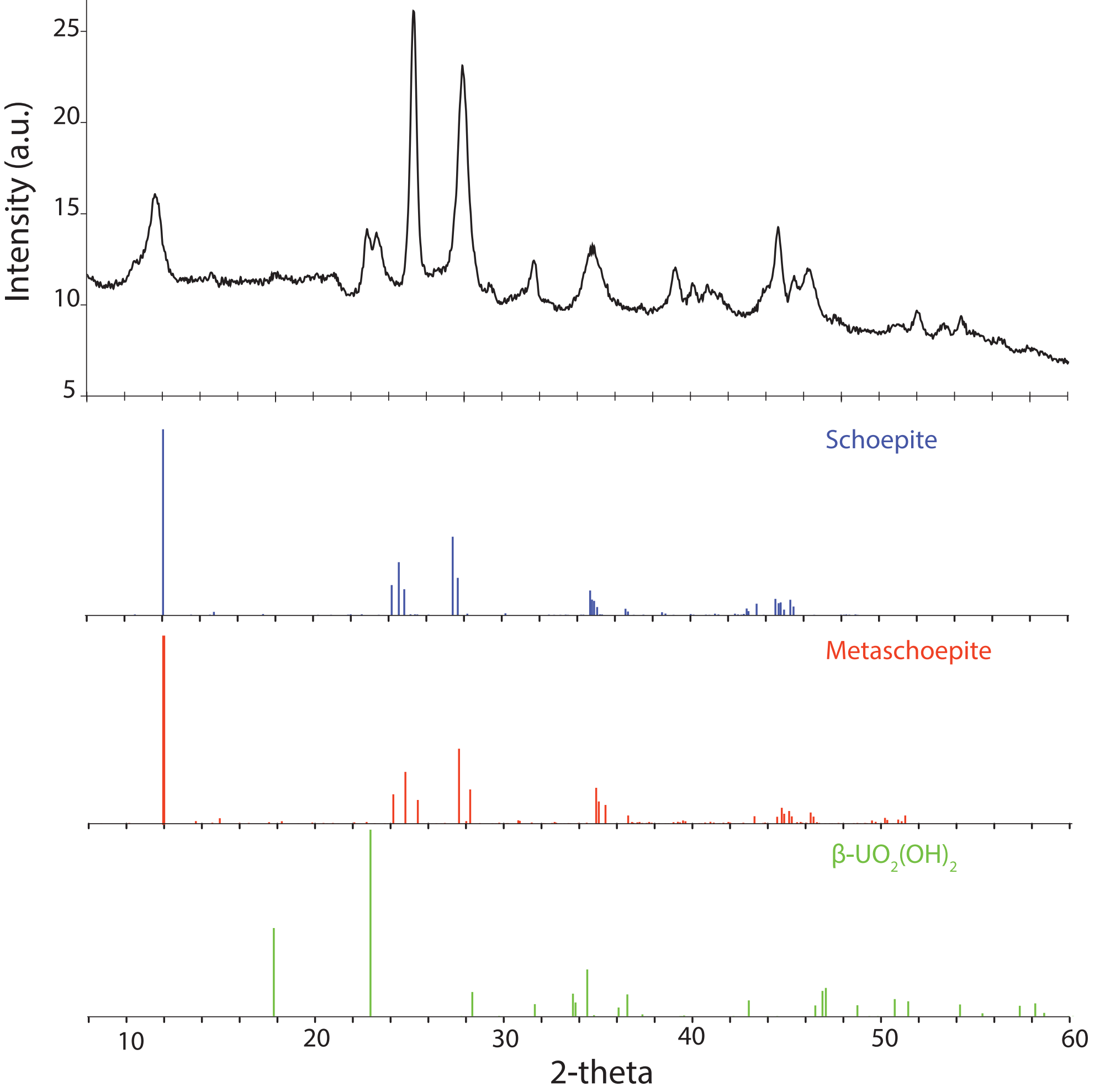


FigErre 6 color

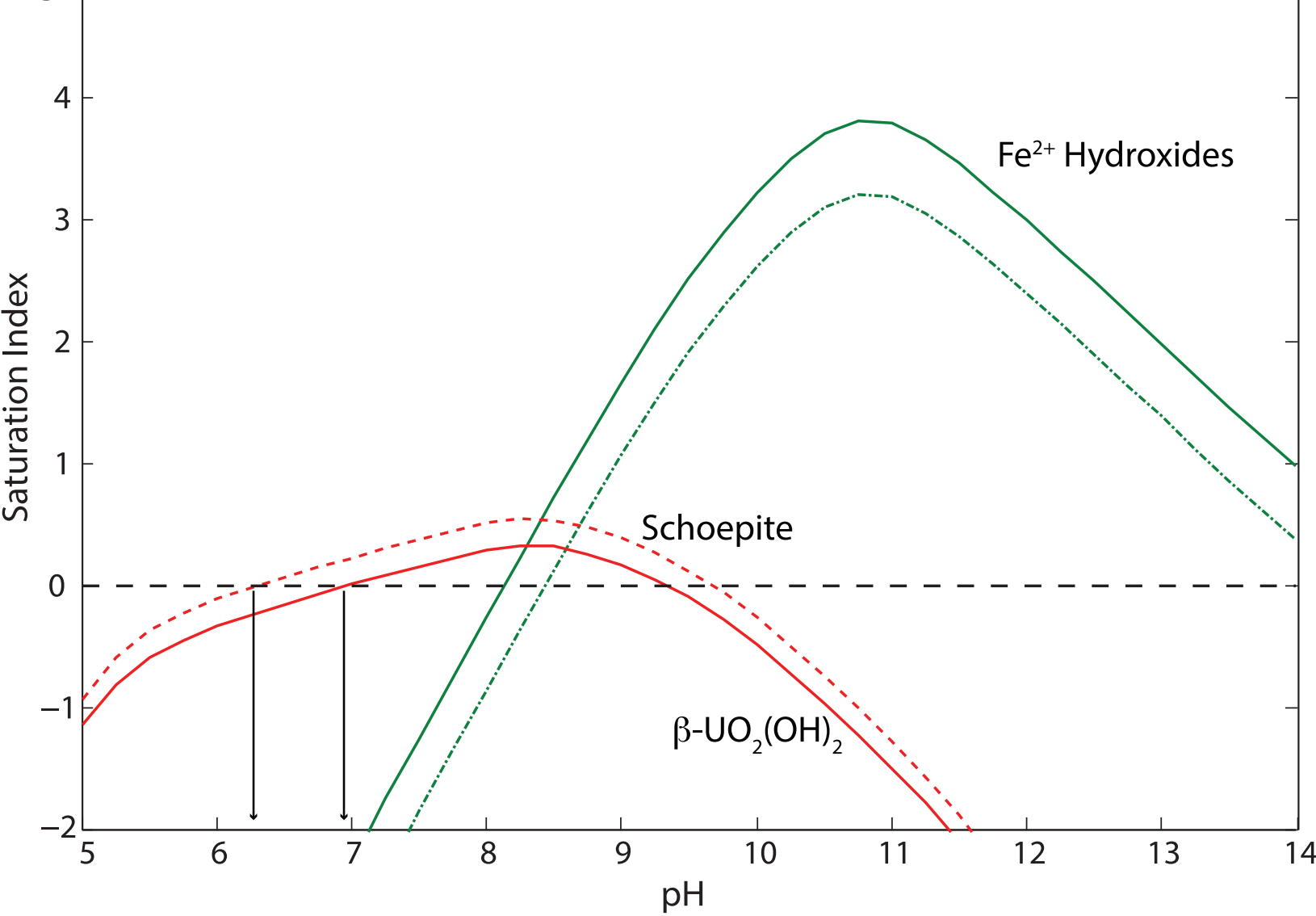


Figure 8 color

(A) 8 col Ka

Acc.V Spot Magn Det WD

$15.0 \mathrm{kV} 3.0 \quad 19096 \mathrm{x}$ SE 12.7

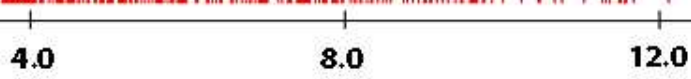

12.0

16.0

20.0

keV

(B)

Al Ka

Acc. $V$ Spot Magn Det WD

$15.0 \mathrm{kV} 3.0 \quad 11151 \times$ BSE 12.5

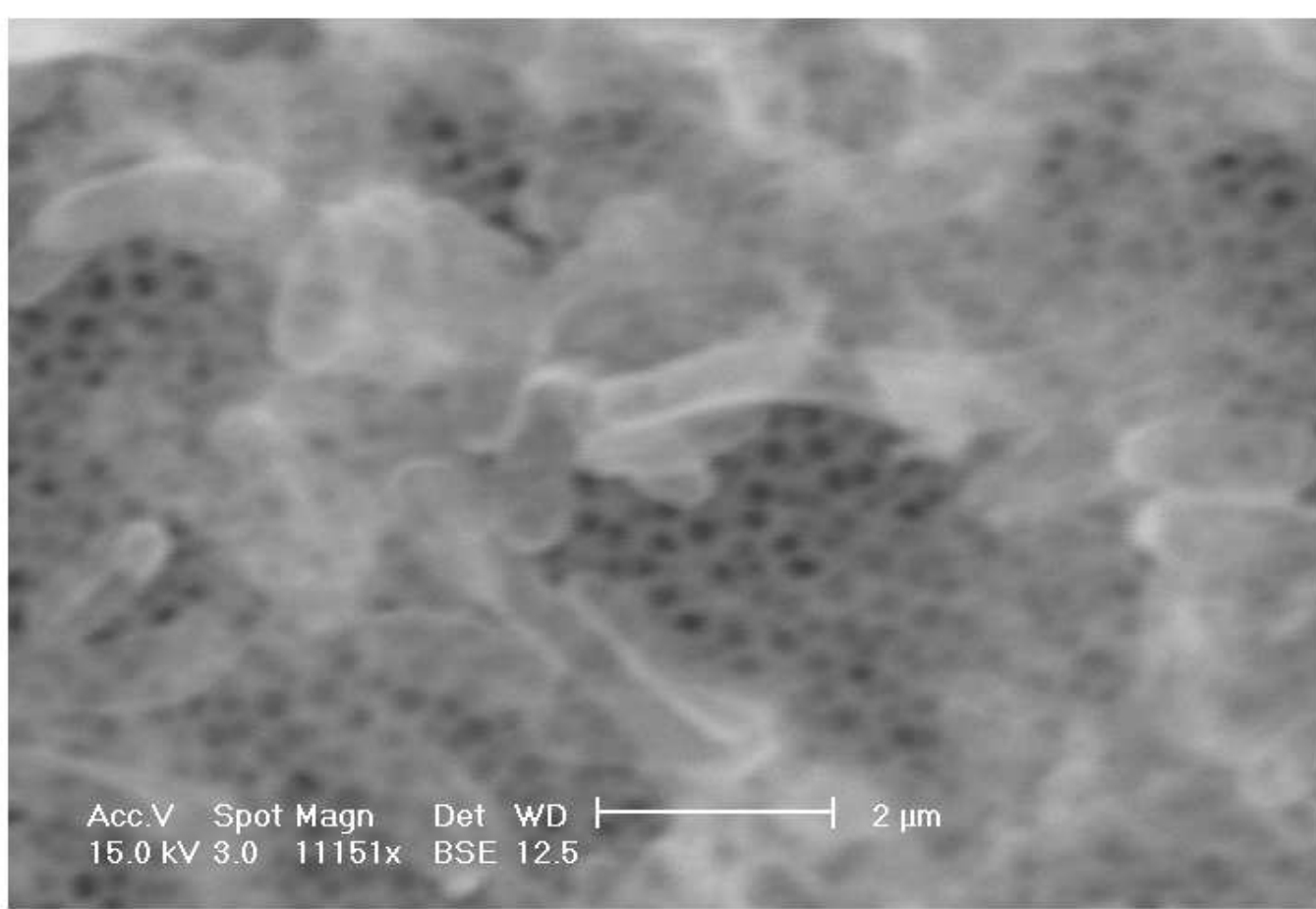

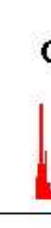

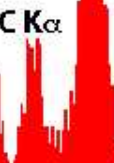

$\mathrm{NaK \alpha}$

0.7

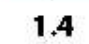

UMa

3.5

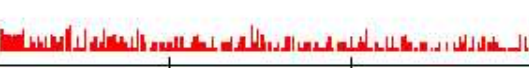

42

4.9

5.6

6.3

$7.0 \quad \mathrm{keV}$ 


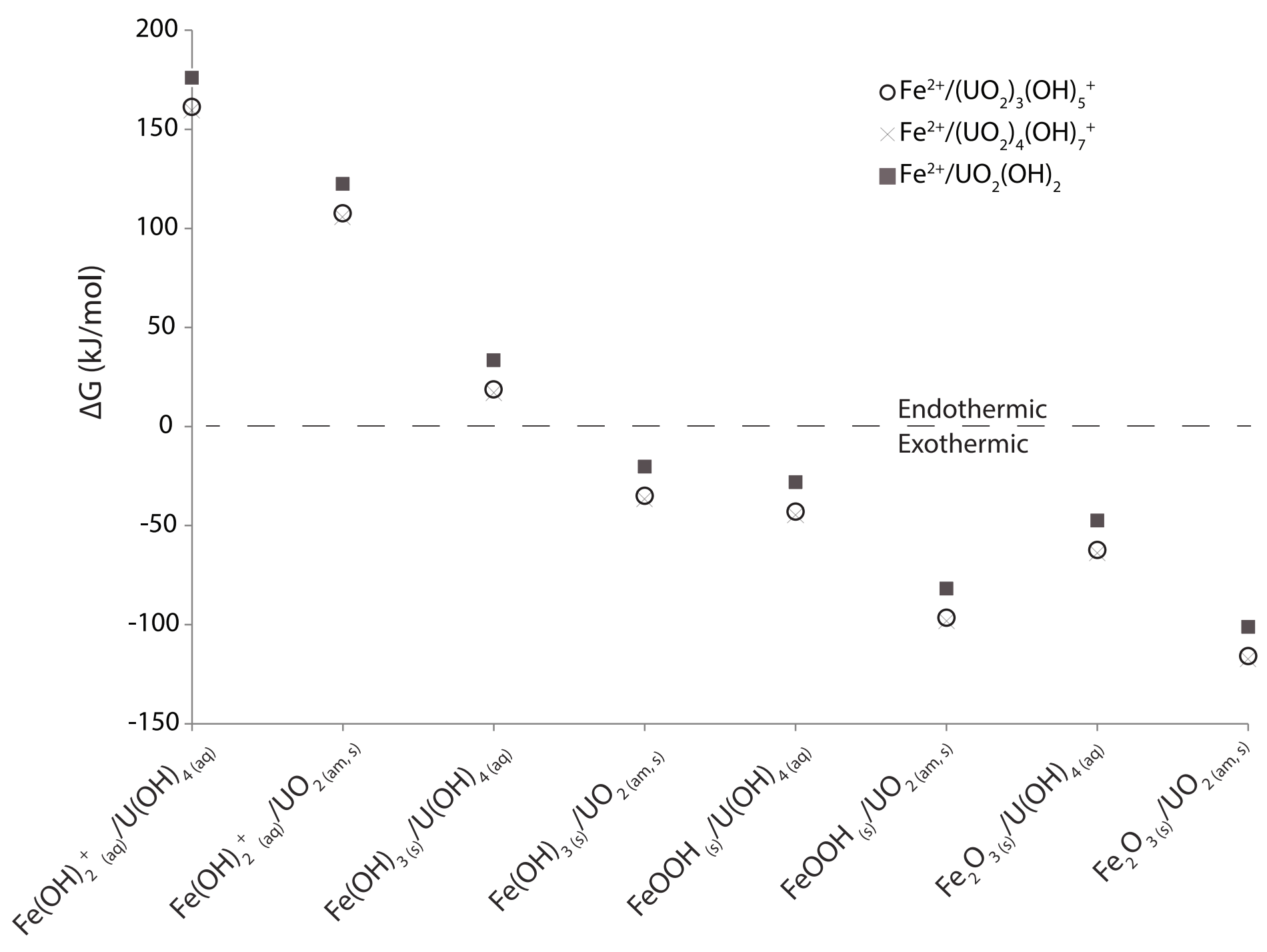


(A) Pre-ET: $\mathrm{Fe}^{2+}-\mathrm{U}^{6+}$

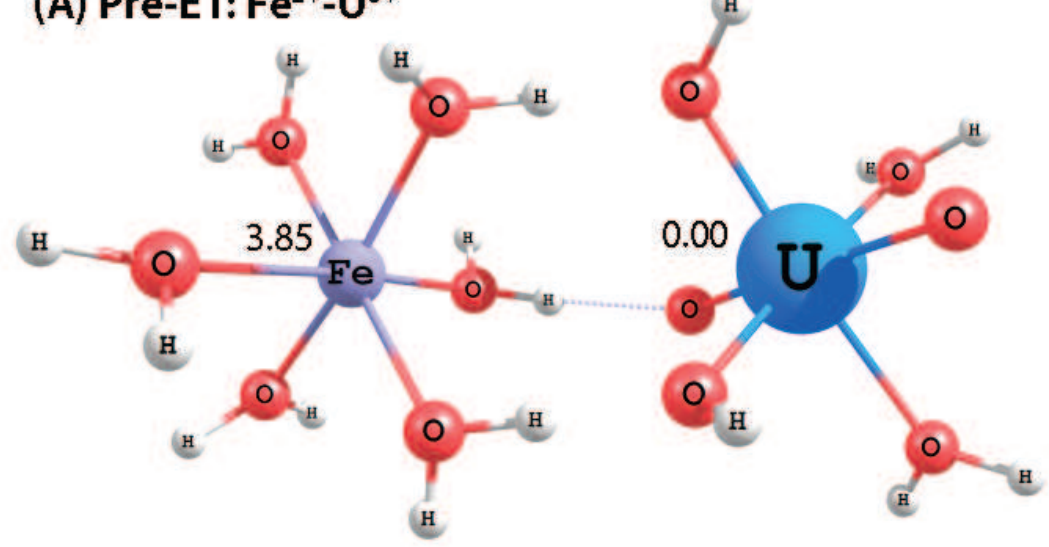

(C)

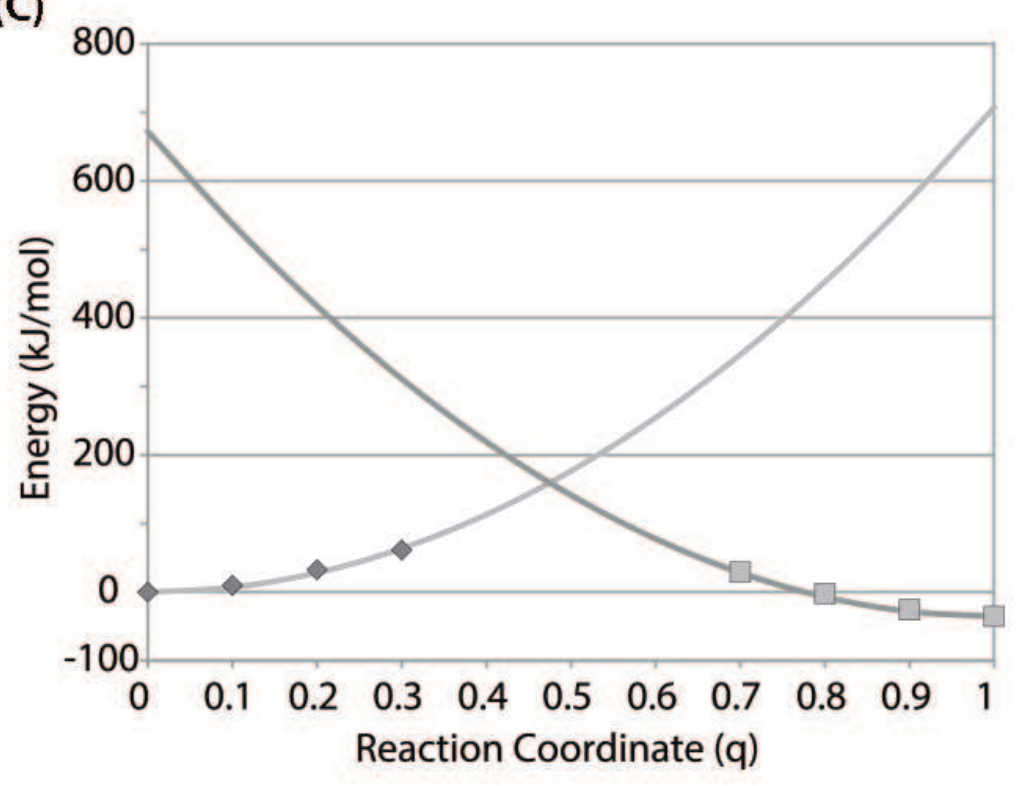

(B) Post-ET: $\mathrm{Fe}^{3+}-\mathrm{U}^{5+}$
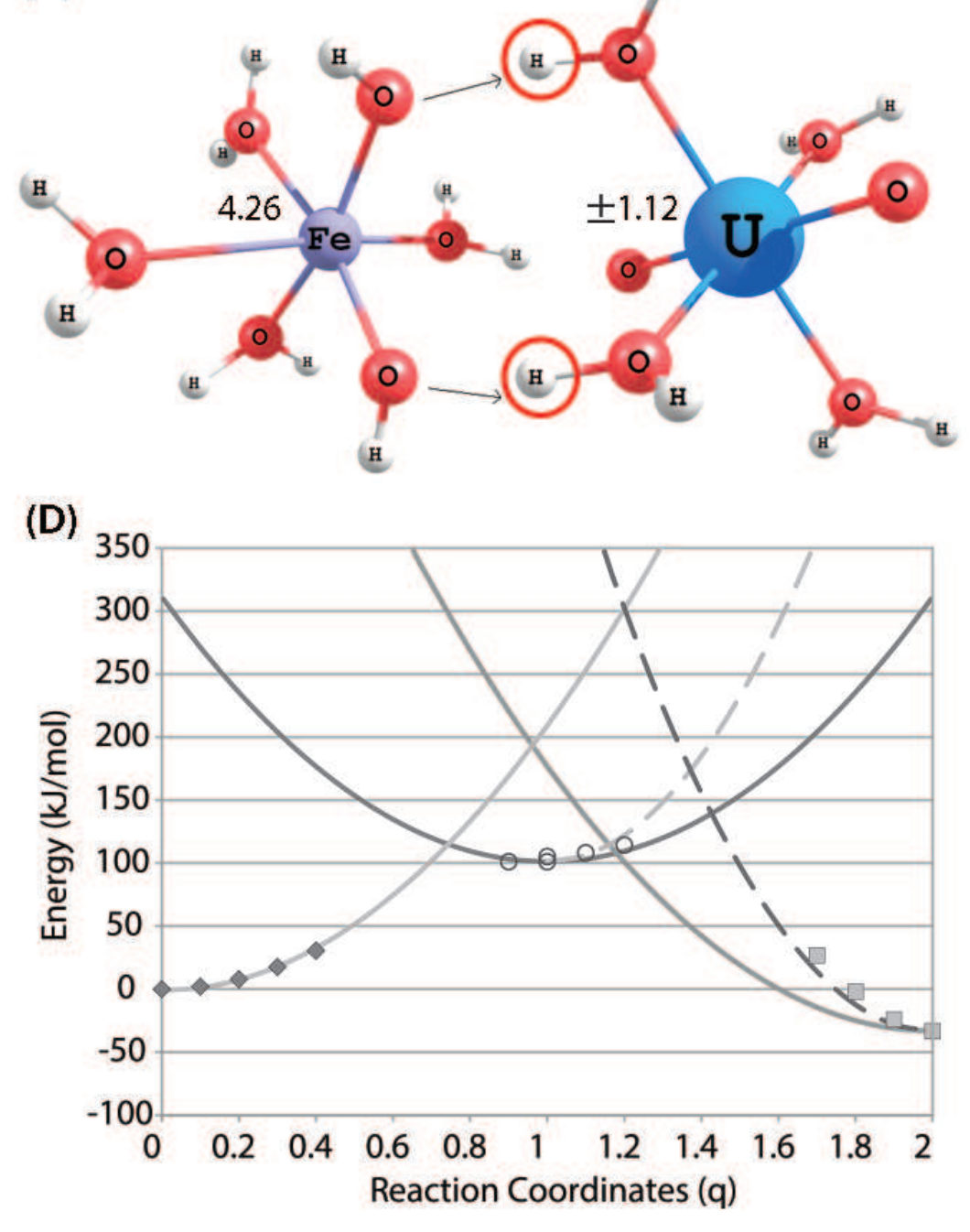
Figure 11 color
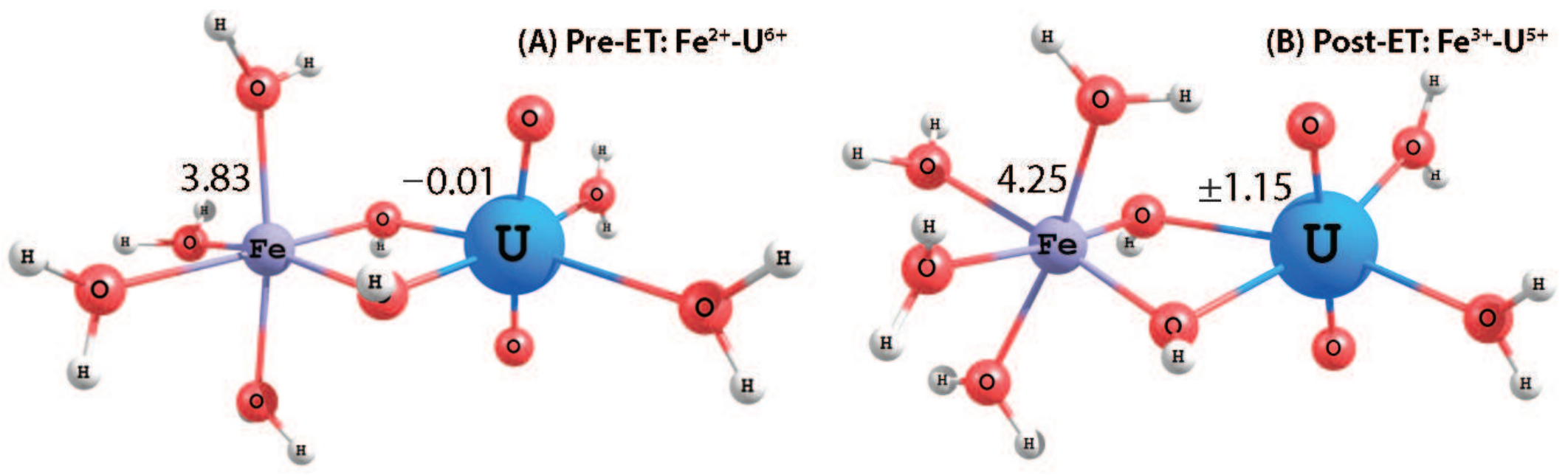

(C)

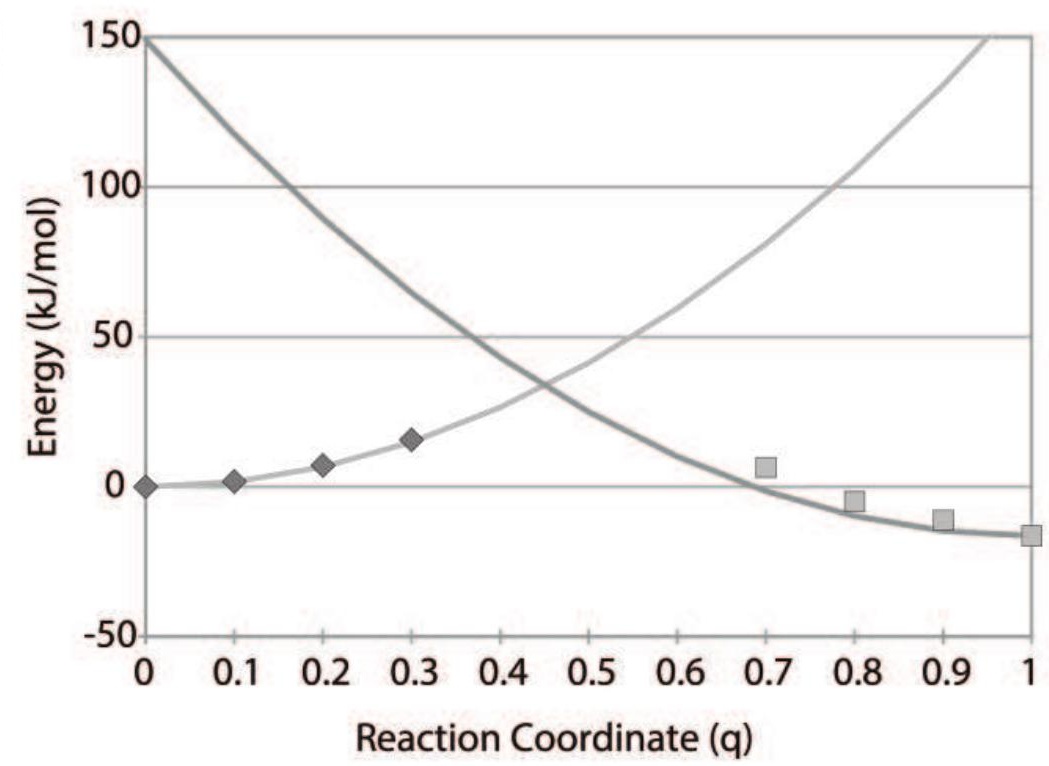




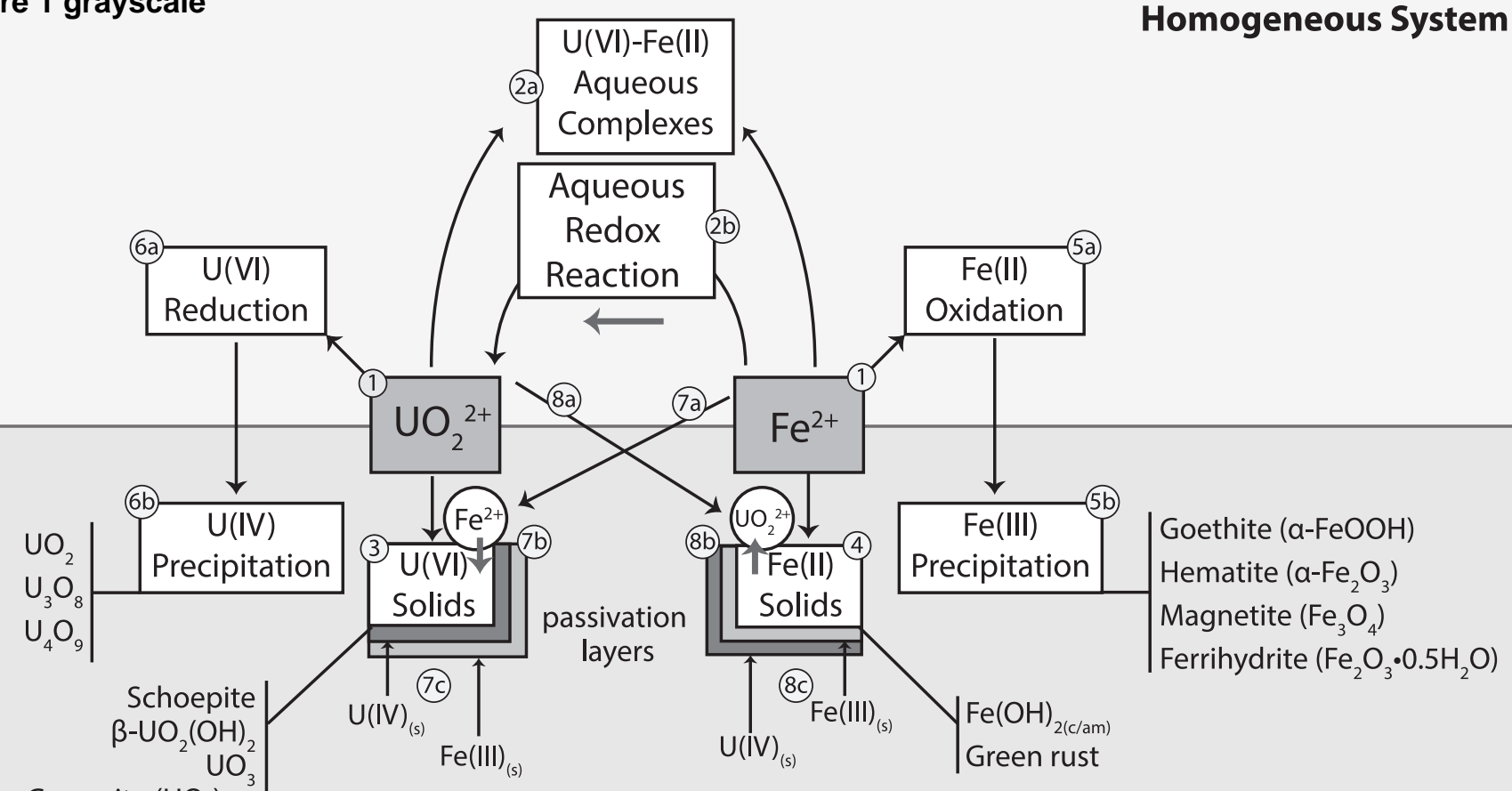

Gummite $\left(\mathrm{UO}_{3}\right)_{(\mathrm{am})}$ 

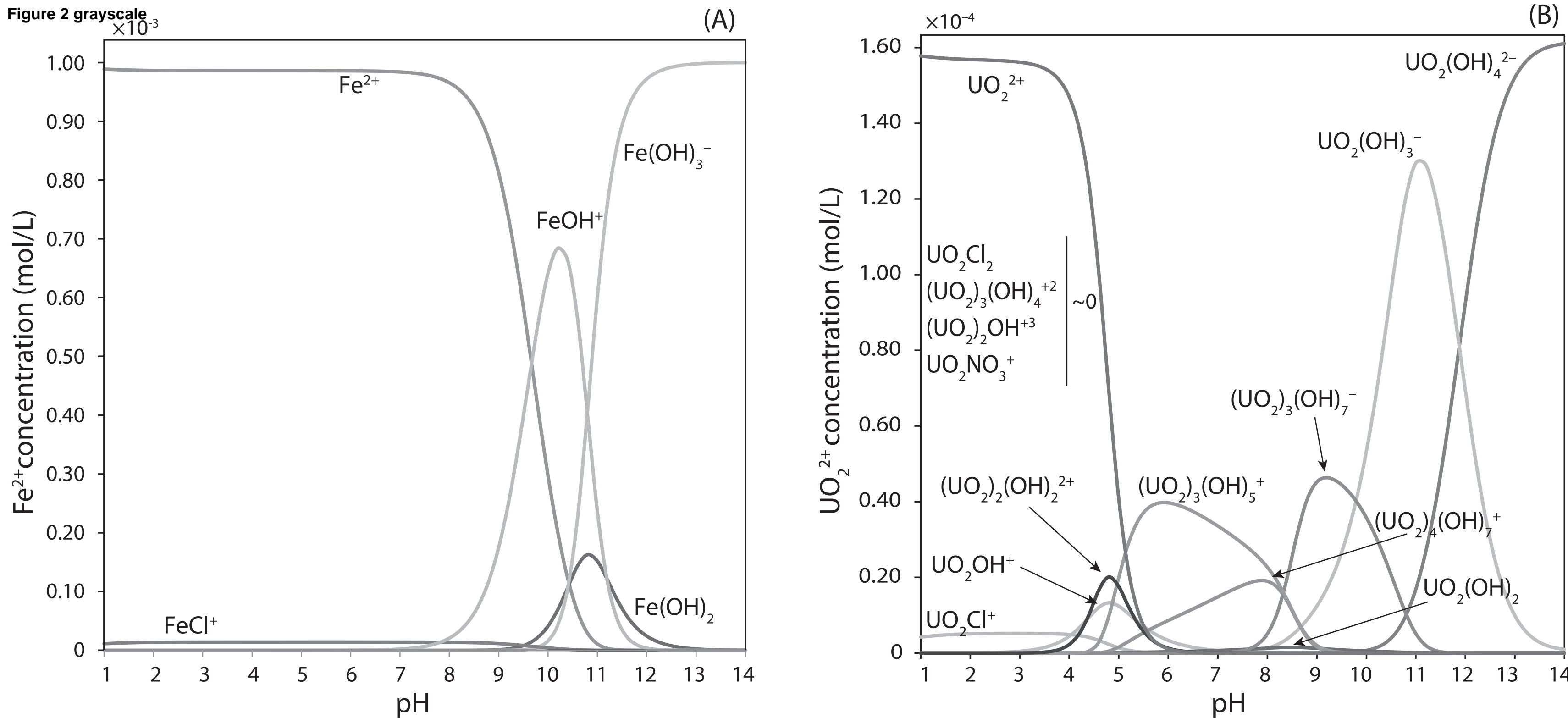
Figure 3 grayscale

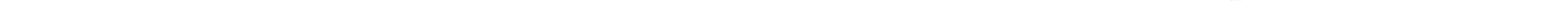


Figure 5 grpyscale

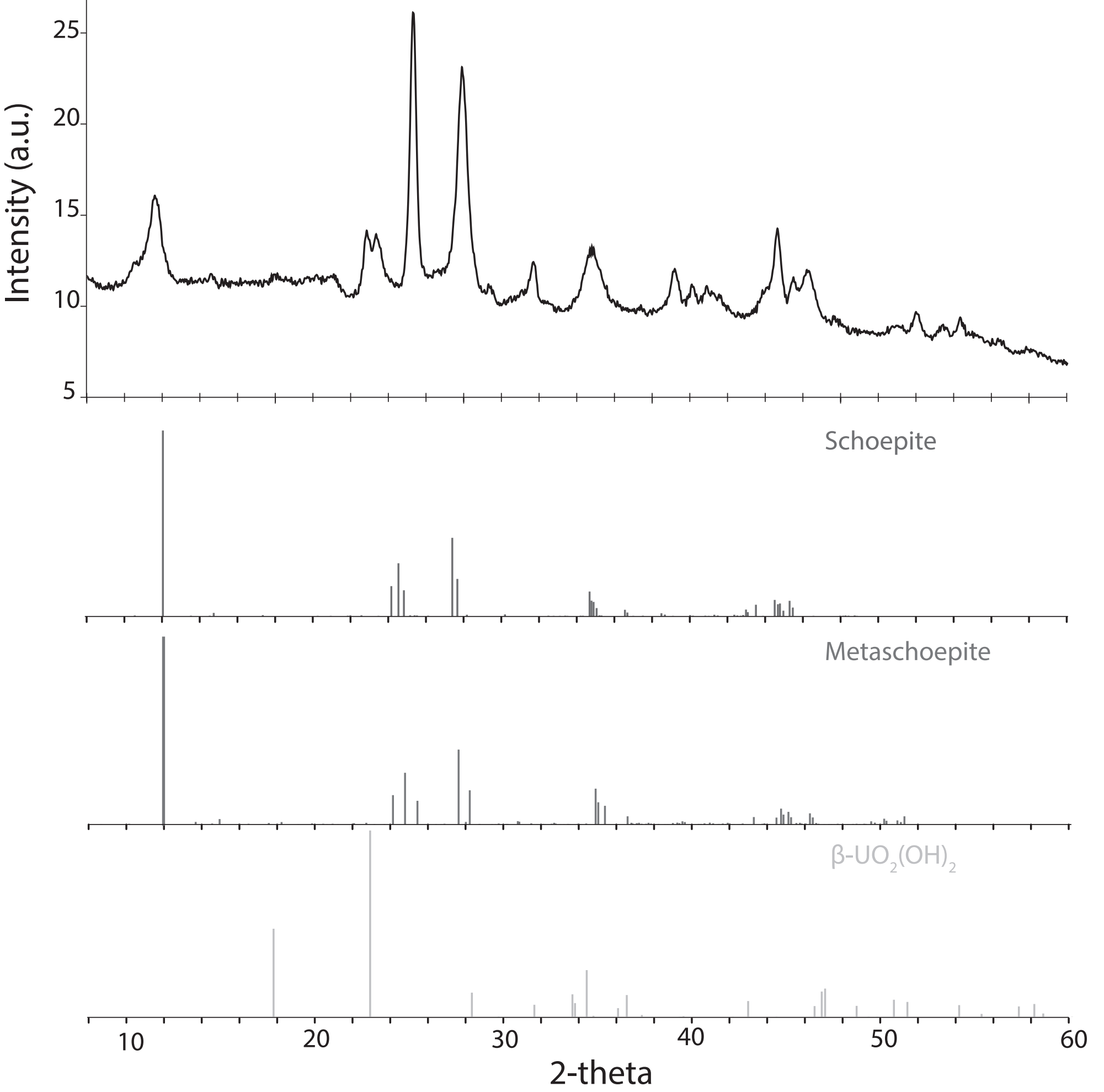




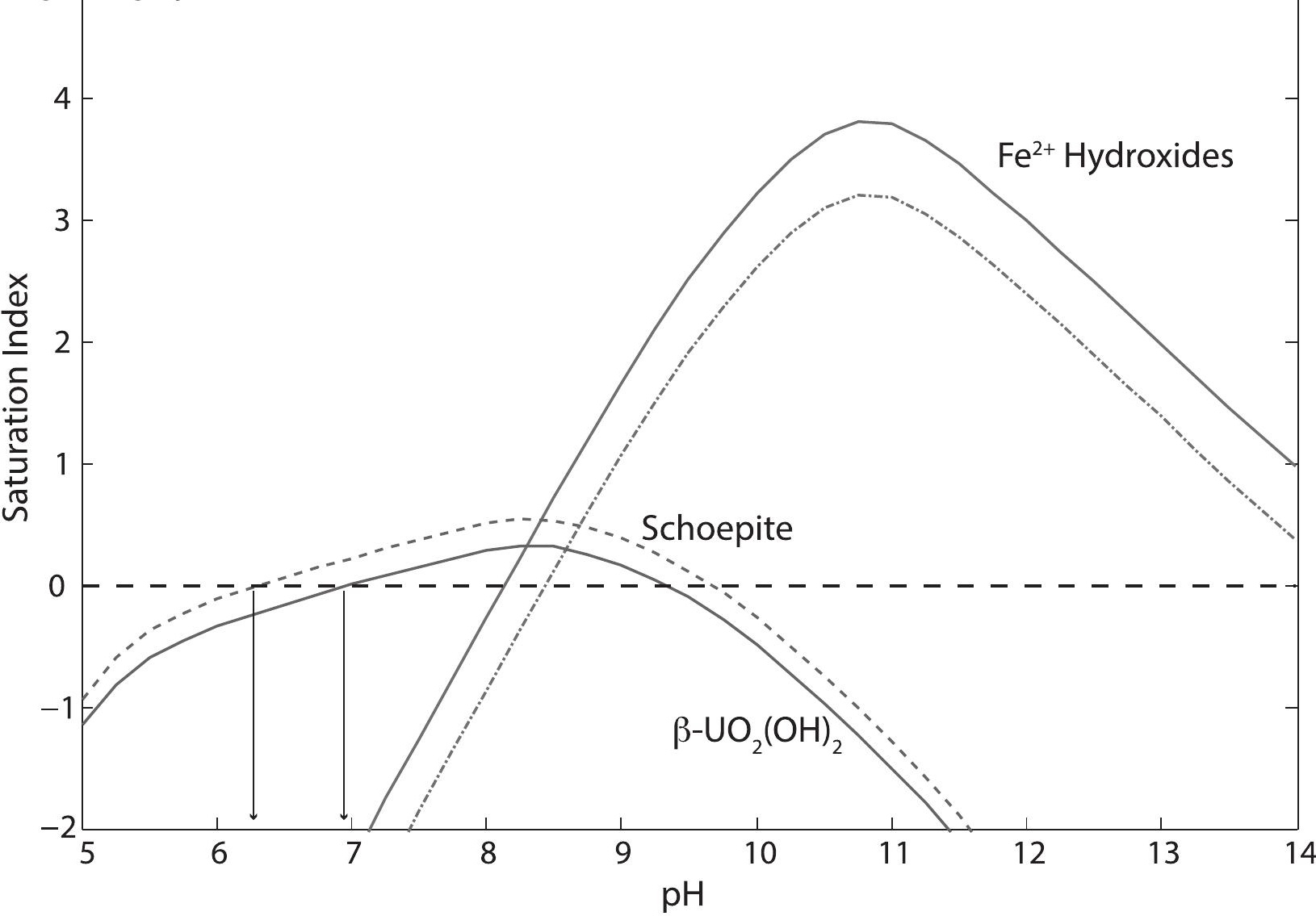




\section{(A) $\mathrm{Al} \mathrm{Ka}$}

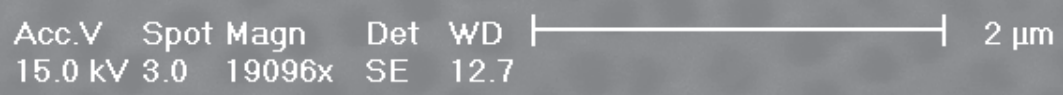

$\mathrm{OK \alpha}$

$\mathrm{CKa}$

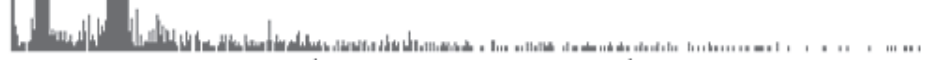

$\begin{array}{lll}4.0 & 8.0 & 12.0\end{array}$

12.0

Al Ka

(B)

Acc.V Spot Magn Det WD

$15.0 \mathrm{kV} 3.0 \quad 11151 \times$ BSE 12.5

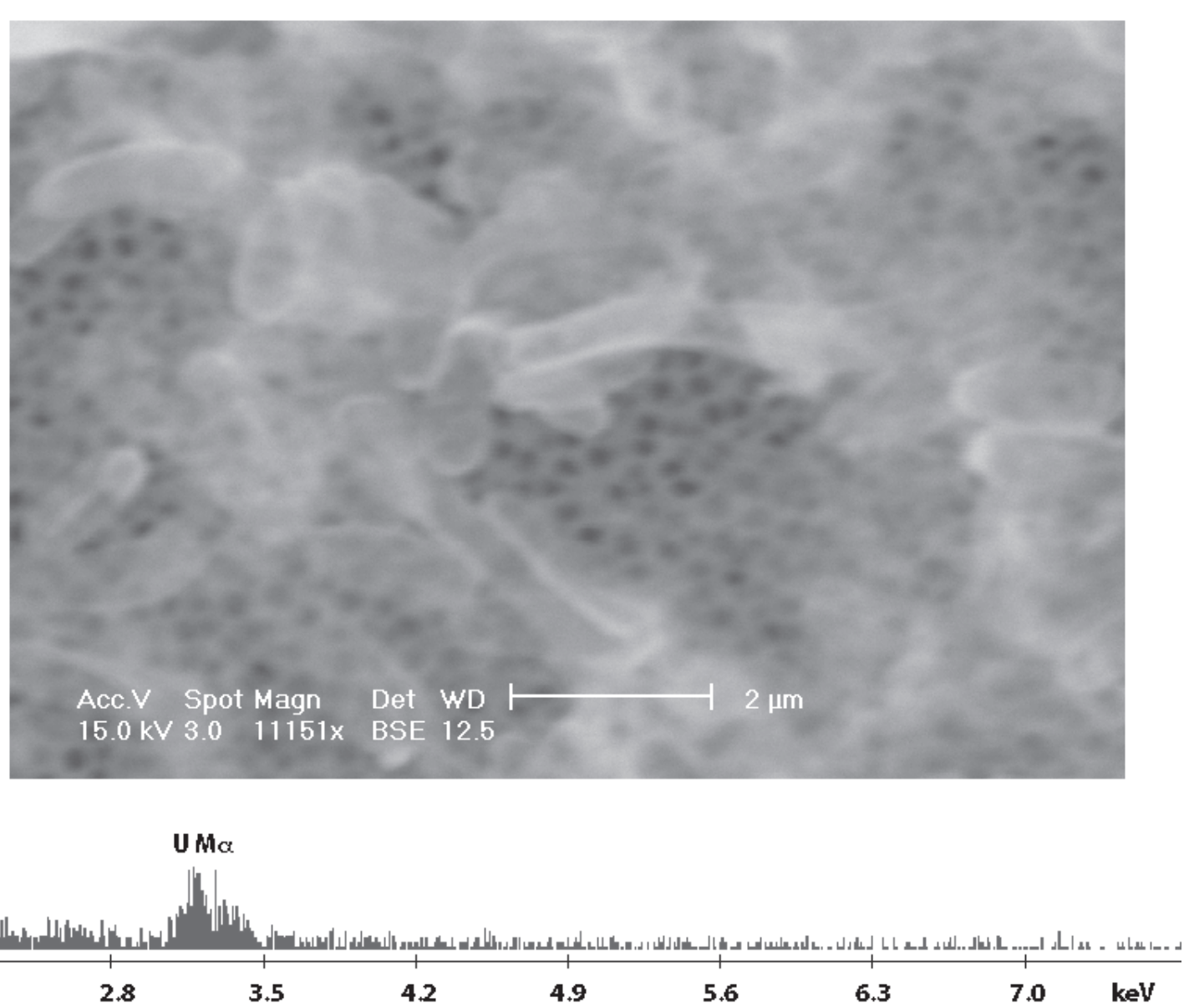




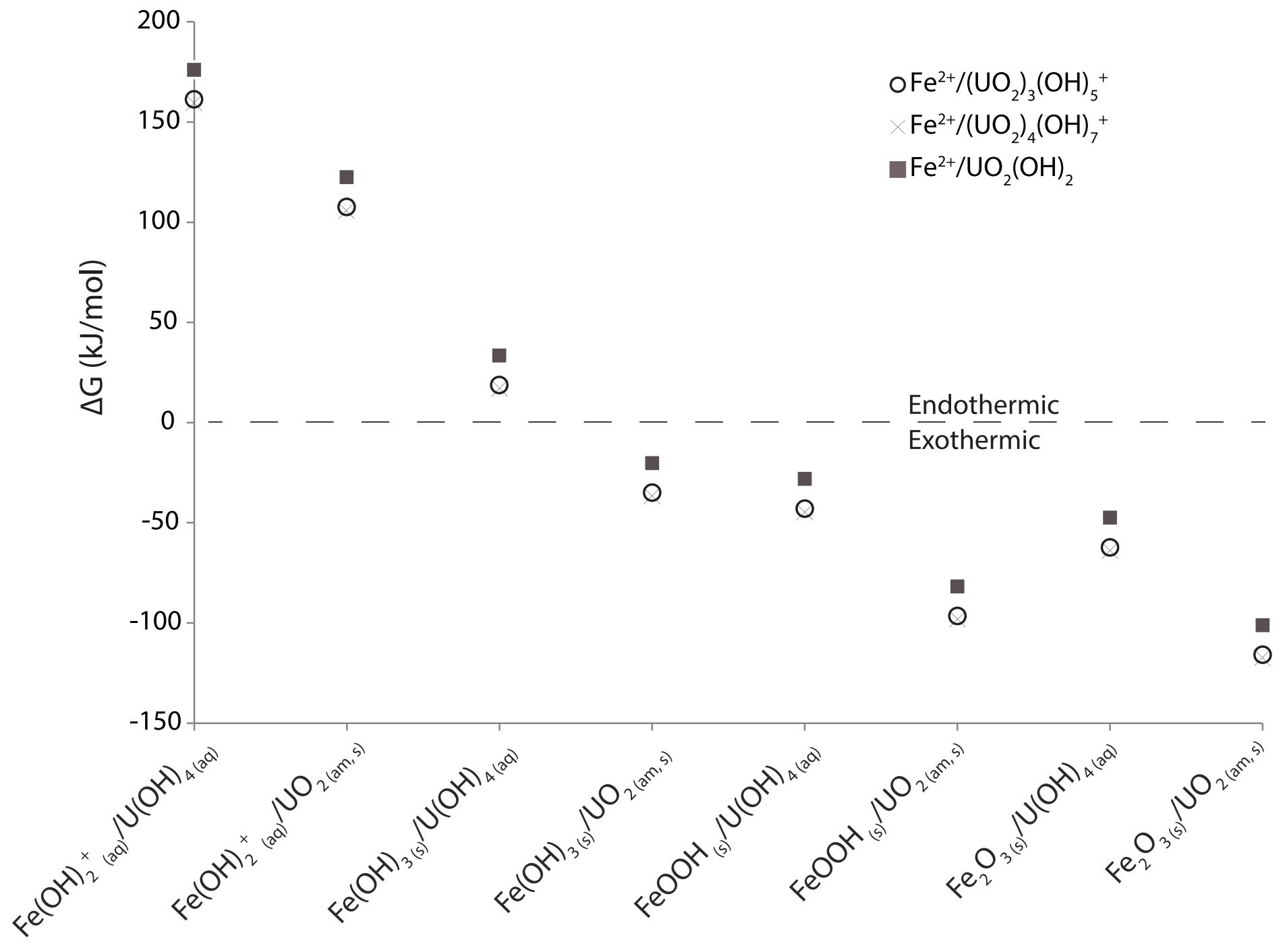



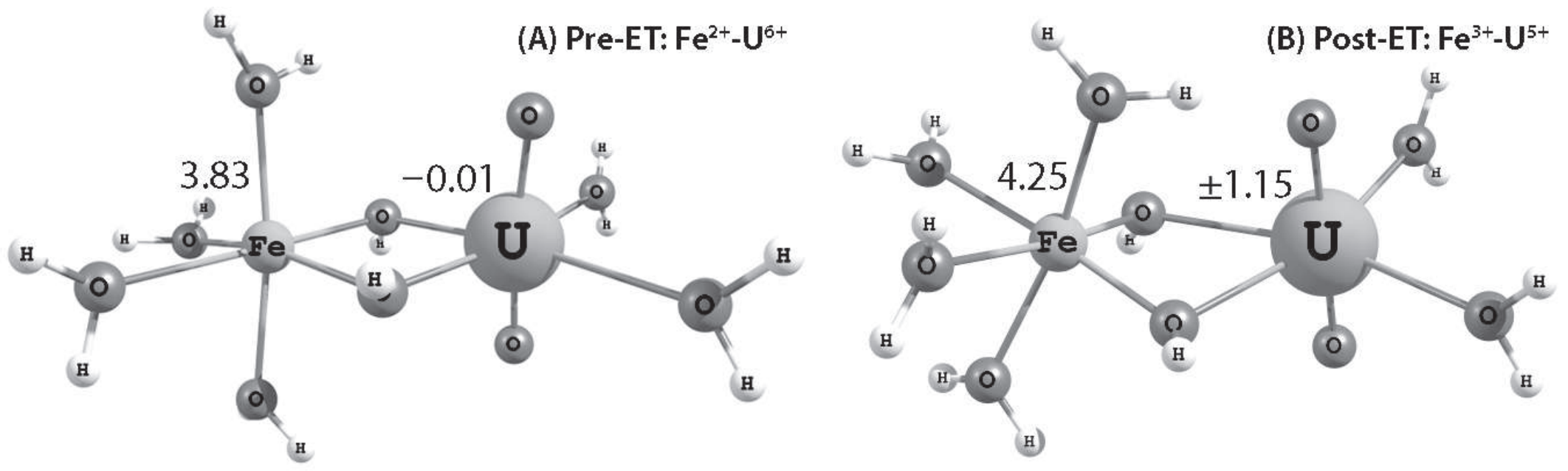

(C)

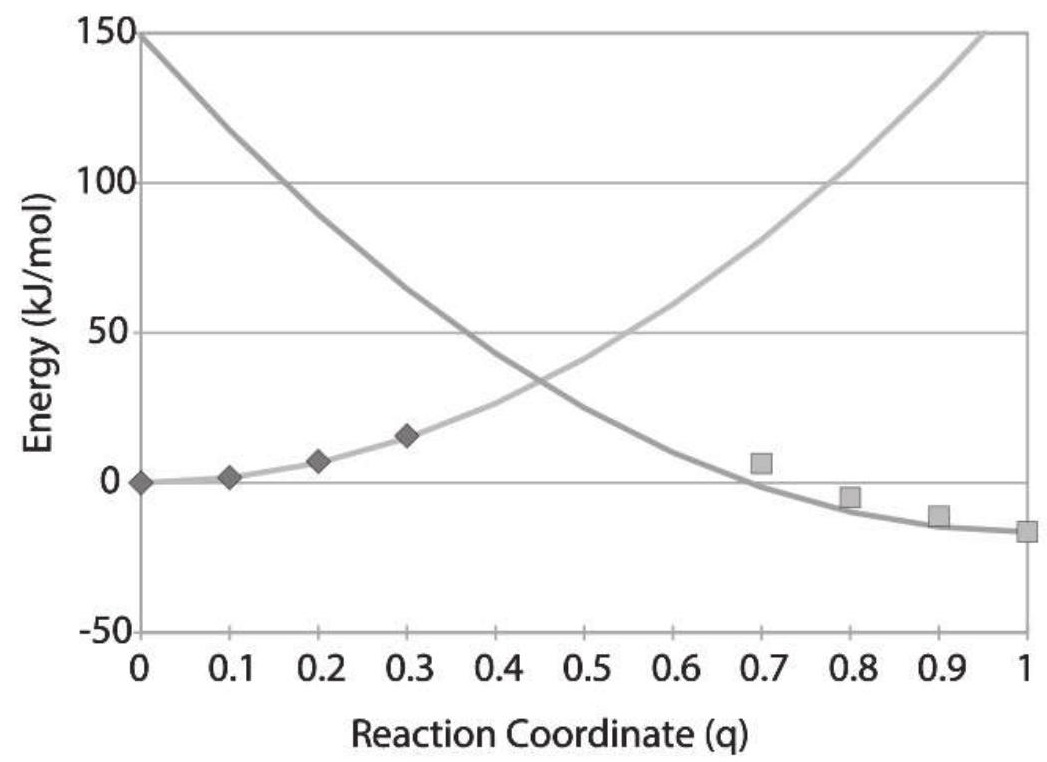

